$<$ Running head verso $>$ Tantucci $<\mathrm{X}>$

$<$ Running head recto $>$ From immediate to extended intersubjectification $<\mathrm{X}>$

\title{
From immediate to extended intersubjectification: a gradient approach to intersubjective awareness and semasiological change
}

\section{VITTORIO TANTUCCI}

Lancaster University

(Received 8 April 2015 - Revised 7 September 2015 - Accepted 19 October 2015)

\section{ABSTRACT}

$<\mathrm{AB}>$ This paper provides a theoretical and methodological contribution to the heated debate on intersubjectivity and intersubjectification (Traugott, 1999, 2002, 2003, 2010, 2012; Nuyts, 2001, 2012; Verhagen, 2005; Narrog, 2010, 2012; Dancygier \& Sweetser, 2012). I will argue that intersubjectivity, intended as a subject's awareness of the other persona(s)' feelings, knowledge, and beliefs, can be construed alternatively on an 'immediate' and on an 'extended' level. Immediate intersubjectivity (I-I) corresponds to the mutual awareness of the speech participants during the ongoing speech event, whereas extended intersubjectivity (E-I) includes an assumed third party (specific or generic) who has an indirect social bearing on the utterance (cf. Tantucci 2013, 2014b). Along a unidirectional cline of change, extended intersubjectification constitutes a further stage of semantic and/or grammatical reanalysis with respect to its immediate counterpart. In order to empirically justify the diachronic continuum between the two, I provide some corpus-illustrated (cf. Tummers et al., 2005, p. 235) examples from Mandarin and corpus-based evidence about the constructions [you don't want X] and believe it or not in American English. $<\mathrm{X}>$

KEYWORDS: immediate intersubjectivity, extended intersubjectivity, intersubjectification, assertivity, idiomaticity, chunking.

\section{Introduction}

This work provides some new theoretical and methodological insights about intersubjectivity and intersubjectification (Traugott, 1999, 2002, 2003, 2010, 2012; Nuyts, 2001, 2012; Verhagen, 2005;

Comment [AS2]: Traugott, ... 2002: Not in Refs.

>> Change into Traugott 2003, 2010 2012; Traugott \& Dasher 2002 
Narrog, 2010, 2012; Dancygier \& Sweetser, 2012). The theoretical framework of this study is based on Tantucci's (2013, 2014b) distinction between immediate and extended dimensions of intersubjectivity. While the former is bound to the mutual awareness of speaker/writer and addressee/hearer (IMMEDIATE INTERSUBJECTIVITY, I-I), the latter includes an assumed third party (specific or generic) who has a social bearing on the utterance (EXTENDED INTERSUBJECTIVITY, E-I) (cf. Tantucci, 2013, 2014b). The main claim of this work is that, along a unidirectional cline of change (cf. Traugott, 1999, 2002, 2003, 2010, 2012), extended intersubjectification constitutes a further stage of semantic and/or grammatical reanalysis with respect to its immediate counterpart. This approach is theoretically and methodologically compatible with the most recent and influential accounts of intersubjectivity and intersubjectification (cf. Traugott, 1999, 2002, 2003, 2010, 2012; Nuyts, 2001, 2012; White, 2003; Martin \& White, 2005; Verhagen, 2005; Narrog, 2010, 2012; Dancygier \& Sweetser, 2012), yet it provides new operational tools to study the relationship between semasiological change and intersubjective construing. The diachronic continuum from immediate to extended intersubjectification that I will discuss in this paper is thus aimed at providing a theoretical and methodological complement to the studies proposed in the literature.

This work is organized as follows: in Sections 2.1 and 2.2, I provide a general overview of the notion of intersubjectivity in the literature and a theoretical and empirical distinction between immediate (I-I) and extended intersubjectivity (E-I). In Section 3, I provide some corpus-illustrated ${ }^{1}$ (cf. Tummers, Heylen, \& Geeraerts, 2005, p. 235) evidence about the diachronic continuum from II to E-I through the analysis of the construction 干嘛 gànma 'do what' in Mandarin. In Section 4, I discuss the applicability and the theoretical relevance of the present framework to the most recent studies on intersubjectification. Section 5 is then dedicated to two corpus-based studies about the I-I and E-I process of the constructions [you don't want X] and believe it or not in American English.

\section{Intersubjectivity: immediate vs. extended}

In this section I will provide a brief overview of the notion of intersubjectivity. I will then draw a conceptual and empirical distinction between immediate (Section 2.1) and extended (Section 2.2) intersubjectivity.

\subsection{INTERSUBJECTIVITY: AN OVERVIEW}

In cognitive psychology, intersubjectivity is generally discussed with reference to the so-called theory of mind (ToM) or mindreading (i.e., Goldman, 2006). More specifically, ToM refers the ability to attribute mental states - beliefs, intents, desires, pretending, knowledge, etc. - to oneself

\footnotetext{
${ }^{1}$ In Section 2.3, I provide a detailed description of this terminology.
}

Comment [AS3]: Traugott, ... 2002: Not in Refs.

>> Change into Traugott 2003, 2010, 2012; Traugott \& Dasher 2002

Comment [AS4]: Traugott, ... 2002: Not in Refs.

>> Change into Traugott 2003, 2010, 2012; Traugott \& Dasher 2002

Comment [AS5]: Section 2.1: Should this be Section 2.3?

>> Yes, please.

Comment [AS6]: Section 2.2

Should this be Section 2.4?

>> Yes, please. 
and others and to understand that others have beliefs, desires, and intentions that are different from one’s own (Premack \& Woodruff, 1978). In linguistics, Benveniste is the first who points out that "discourse [...] is language in so far as it is taken over by the man who is speaking and within the condition of intersubjectivity, which alone makes linguistic communication possible” (Benveniste, 1971 [1958], p. 230). In pragmatics the term 'interpersonal' is traditionally adopted to refer to a similar phenomenon: 'interpersonal rhetoric' and 'interpersonal pragmatics’ (Leech, 1983; Locher \& Graham, 2010) all mainly have to do with relations and attitudes adopted to convey strategically (im)politeness and other pragmatic functions. From a similar perspective, Brown and Levinson's (1987) study exemplifies in detail the interactants' interpersonal relations in the study of how im/politeness is negotiated, with a particular stress on the metaphor of 'face' and so-called 'facethreatening acts'. In their framework, face is "the public self-image that every member wants to claim for himself [sic]” (Brown \& Levinson, 1987, p. 61), while face-threatening acts are "acts that by their nature run contrary to the face wants of the addressee and/or of the speaker” (p. 65).

Intersubjectivity is also discussed by Schriffin (1990, p. 142), who defines it as the interaction between an actor's actions - intended to be perceived and designed as such and actions not so intended - and an audience's interpretation of all the information stated and implied. From a more cognitive perspective, Verhagen (2005) grounds his analyses in argumentation theory (Ascombre \& Ducrot, 1989), focusing mostly on the cognitive construals activated by the SP/W ${ }^{2}$ and shared by the $\mathrm{AD} / \mathrm{R}^{3}$ when an intersubjective construction/strategy comes into play. He emphasizes that human communication is primarily a matter of influencing rather than informing one another. Every construing process is motivated by the presence - actual or virtual - of a SP/W and an $\mathrm{AD} / \mathrm{R}$ sharing the conceptual representation of what is said. According to Verhagen's framework, there is not a real boundary between subjectivity (cf. Lyons, 1982; Langacker, 1990, 2002, 2006, 2008; Smith, 2003; Traugott, 1989, 2003) and intersubjectivity in the sense that every subjective construing process leading to an utterance is aimed at communicating some idea to a more or less specific interlocutor.

\subsection{DIACHRONIC APPROACHES TO INTERSUBJECTIVITY: (INTER)SUBJECTIFICATION}

Different from Verhagen, Traugott (2012) stresses that subjectivity and intersubjectivity are two related phenomena which can nonetheless be differentiated empirically. It is obvious how on the conceptual plane any speech-event will involve intersubjectivity to some degree. On the other hand,

\footnotetext{
${ }^{2}$ Speaker/writer.

3 Addressee/hearer.
}

Comment [AS7]: Benveniste, 1971 [1958], p. 230: Not in Refs.

$>>$ Added to Refs (highlieghted in yellow).

Comment [AS8]: im/politeness: Is it OK to have "im/politeness", as here, and "(im)politeness", as above?

>> Change the latter into (im)politeness please. 
the conceptual awareness of the 'self' (subjectivity) and the 'self' plus the other persona involved in the interaction (intersubjectivity) can be alternatively profiled through specific linguistic coding. According to Traugott's distinction, the former represents the meaning indexing speaker attitude and viewpoint, whereas the latter involves to a greater degree the SP/W's attention on the AD/R's self-image.

What is distinctive in her framework is the effective applicability of (inter)subjectivity to diachronic phenomena of semantic and or grammatical reanalysis. Subjectified polysemies may occur in evaluations of others, e.g., silly which originally meant 'blessed, innocent', but later on came to be reanalysed as 'stupid'. Subjectification may similarly affect / relate to the relative position on a scale: take an adverb like pretty 'cleverly', which was successively used with the implied meaning of 'attractively' and later also as a modifier with a function similar to 'rather' (Traugott, 2010, p. 32). Similar to Traugott, Sweetser points out that subjectification can involve the attitude toward the truth of a proposition, as observable in the shift from the deontic to the epistemic meaning of must (Sweetser, 1990, p. 61). Similarly, Tantucci provides a statistical model to observe the diachronic increase of certainty of epistemic verbs as a process of subjectification (cf. Tantucci, 2014a). A more fine-grained account of different construals of subjectivity is given by De Smet and Verstraete (2006, p. 385) who provide a distinction between pragmatic usages, ideational usages (having to do with meanings pertaining to the extra-discursive world), and interpersonal usages of a construction (semantically addressing the interaction between SP/W and AD/R).

That being said, as Traugott points out, a prominently intersubjective reanalysis of a construction involves the semantic shift from a more SP/W's centred meaning (comparatively more subjective) to a new one focusing mostly on the $\mathrm{AD} / \mathrm{R}$ (comparatively more intersubjective). She provides evidence for discourse markers in English functioning as hedges, constructions encoding politeness (as in the case of the more schematic please from the formulaic if you please) or impoliteness, euphemisms (pass away for die) and others.

\subsection{IMMEDIATE INTERSUBJECTIVITY}

Whether it is from a synchronic or a diachronic perspective, all the accounts of intersubjectivity discussed so far are mainly centred on the here-and-now of the conversation, or in other words, the awareness that the speakers have of each other during a speech event or a connection. As an illustration, consider the intersubjectified meaning of actually discussed by Traugott (2003, p. 129) in the examples below:

$<$ LDIS>

(1) I will drive you to the dentist.

(2) Actually, I will drive you to the dentist.

Comment [AS9]: Sweetser, 1990, p. 61: Not in Refs.

$>>$ Added to refernces (highlighted in yellow). 
$<\mathrm{X}>$

In (1) the SP/W does not mark overtly his awareness of the interlocutor as a subjective 'other persona' with specific attitudes, and feelings. Conversely, with the use of actually in (2) SP/W prevents $\mathrm{AD} / \mathrm{R}$ 's from disagreeing with the proposition, with an implied attempt to mitigate it. The latter could be paraphrased as Aware of what you might say, I am telling you P. In this sense, the intersubjective awareness conveyed by actually in (2) does not exceed the here-and-now of the conversation, as it only pertains to SP/W and AD/R. In Tantucci (2013, p. 217; 2014b) this type of intersubjective dimension is defined as immediate intersubjectivity. I-I is generally limited to the two actual personas - SP/W and AD/R - engaging in the conversation and their respective inferred feelings and attitudes.

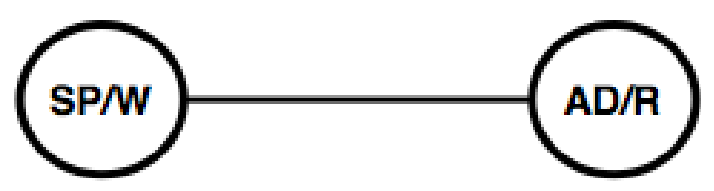

$<$ Figure 1 about here $>$

Fig. 1. Immediate intersubjectivity (from Tantucci, 2013, p. 217)

The line sketched in Figure 1 symbolically connects the interlocutors' minds during the speech event. The main point of Figure 1 is to represent I-I as a mirrored form of awareness simply limited to the speech participants (SP/W and AD/R).

\subsection{EXTENDED INTERSUBJECTIVITY}

A point that in the literature has been often neglected is that intersubjective awareness can also go beyond the boundaries of the here-and-now of the speech event and reach other specific personas, groups of people, or even society as whole. At this point, the notion of 'you' turns into the notion of ‘you and someone else(s)' and a proposition $\mathrm{P}$ acquires an indirect social deixis. Consider again the pair below (from Tantucci, 2013, p. 218):

$<$ LDIS $>$

(1) I will drive you to the dentist.

(2) (a) Actually, I will drive you to the dentist, I've just spoken with your mother. $<\mathrm{X}>$

Actually in (2a) does not simply encode SP/W's awareness of him/herself and the AD/R as two isolated interlocutors, but also exceeds the immediate ground of the conversation, including a third 
party (3rdP), specifically AD/R's mother (Tantucci, 2013, p. 218). ${ }^{4}$ Different from (2), in SP/W's mind the speech event is here characterized by a more extended construal, ${ }^{5}$ corresponding to what Tantucci (p. 218) defines as extended intersubjectivity. Accordingly, E-I is to be intended as a form of emotional or epistemic awareness by which the SP/W takes into account him/herself, the AD/R and a 3rdP in society. The latter, depending on the construal activated by SP/W, can be singular or plural, specific or impersonal. In other words, 3rdP is the symbolic notion of a 'someone else' who can be assumed to potentially confirm the truthfulness of a SP/W's statement or the acceptability of his/her attitudes or emotional reactions. 3rdP is an assumed social persona indirectly supporting the conversation, personally or impersonally determining what is to be approved or denied emotionally or epistemically between the two interlocutors.

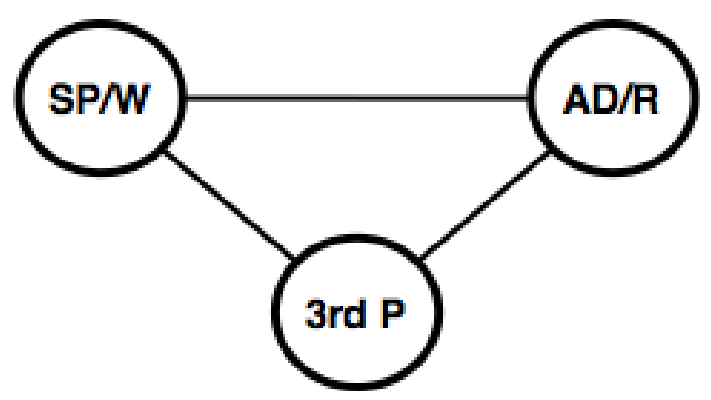

$<$ Figure 2 about here $>$

Fig. 2. Extended intersubjectivity (Tantucci, 2013, p. 218; 2014b)

In Figure 2, the speech participants are deictically connected to a 3rdP, a 'someone else' who is assumed to potentially confirm, approve, or judge the interlocutor's propositions. As we will see, along a semasiological cline of change, the marked awareness 3rdP tends to be intersubjectified as a generic third persona(s), an assumed group of people or even society as a whole. Example (3) is from the spoken section of the BNC (British National Corpus) and is characterized by an E-I usage of actually:

$<$ LDIS $>$

(3) They had to perhaps give up their pots and pans, or they were supposed to. Actually, a remarkably few were collected, to provide brass for armaments.

\footnotetext{
${ }^{4}$ This extended-intersubjective meaning of (3) is here intended as one of the possible polysemies that actually acquired with a new discourse marker (DM) function throughout a diachronic process of semasiological reanalysis (cf. Traugott, 2003, p. 170). This point will be discussed in more detail the current section.

${ }^{5}$ In cognitive linguistics, construals are generally defined as "one of the countless ways of conceiving and portraying the situation in question” (cf. Langacker, 2008, p. 4)
}

Comment [AS11]: Footnote 4: Foot note 4 refers to example (3). Should it refer to “(2a)"?

ALSO: The page number for Traugott (2003) does not match the range given in the Refs (124-139).

$>>$ Change (3) into (2a).

$>>$ Change Traugott 2003 into

Traugott \& Dasher 2002 
(BNC KRN 119)

$<\mathrm{X}>$

According to Traugott (2003, p. 170) actually acquired an intersubjectified discourse marker (DM) function in the early nineteenth century "to soften or mitigate what is said with the purpose of acknowledging the addressee's actual or possible objections” (p. 174). In Section 2.1, the construal of this usage is defined as immediate intersubjectivity. This was exemplified in (2), where SP/W employing actually as a DM seems to exclusively take into account the $\mathrm{AD} / \mathrm{R}$ as his/her sole interlocutor.

Quite differently, the grammaticalized usage of actually in (3) represents an instance of a more extended form of intersubjectivity. Formally, it still functions as a DM, as it appears dislocated to a clause-periphery position. As attested in Traugott (2012, p. 7) the clause-periphery dislocation of surely and similar adverbials corresponds to a formal stage of intersubjectification towards a DM function. Similarly, earlier usages of actually functioning as a DM in a clauseperiphery position would necessarily occur in the presence of a specific AD/R.

However, while SP/W's proposition in (3) also profiles the intent to prevent some virtual comment or objection, nonetheless, $\mathrm{AD} / \mathrm{R}$ is no longer a specific interlocutor (s/he could be anyone). In addition to that, SP/W's intersubjective awareness here exceeds the here-and-now of the conversation and reaches a general 3rdP assumed to be also aware of the proposition. That is, rather than functioning as a mere DM, this particular usage of actually conveys interpersonal evidentiality (cf. Tantucci, 2013, 2015) as it marks a proposition as a piece of knowledge shared by SP/W together with some other persona(s) who could potentially confirm the truthfulness of P. In this sense, SP/W here states what S/HE HAS COME TO KNOW, rather than what is REAL/ACTUAL in an absolute sense. This form of construal necessarily needs to include the awareness of an AD/R (more or less bleached) and the one of an external 3rdP, indirectly supporting SP/W's proposition (see Figure 2). A similar intersection between the here proposed extended-intersubjectivty and evidential reasoning is more broadly at issue in Nuyts’ (2001a, 2001b, p. 393) account of intersubjectivity, which he defines as the dimension where SP/W markedly indicates that "s/he is not the only person who has access to the evidence", but is rather part of "a larger group of people who share the same conclusion based on it”.

As an evidential marker, the DM actually in (3) can be felicitously substituted with similar evidential functions such as apparently, as it seems, it is known that, and so on. On the other hand, still functioning as a DM, actually cannot be paraphrased as an evidential when is limited to a more immediate form of intersubjectivity in the Traugottian sense:

$<$ LDIS > 
$[\mathrm{E}-\mathrm{I}]^{6}$

(3)

[...] Actually, a remarkably few were collected, to provide brass for armaments.

(a) It seems that a remarkably few were collected, to provide brass for armaments.

[I-I]

(4) Actually, I wouldn't mind it staying open cos I'm a bit hot.

(a) *It seems that I wouldn't mind it staying open cos I'm a bit hot. (BNC F7G 509)

$<\mathrm{X}>$

As can be easily tested, (4a) actually cannot be substituted by - or paraphrased with - any form of interpersonal evidential construction (i.e., apparently, as it seems, and others) as its intersubjective function exclusively addresses a specific $\mathrm{AD} / \mathrm{R}$. On the other hand, in addition to $\mathrm{AD} / \mathrm{R}$, (3a) is also extended to a general 3rdP who is also assumed to be aware of the proposition, contributing to the emerging evidential meaning of the construction. The E-I entailment of both the awareness of 3rdP and the 'bleached' awareness of $\mathrm{AD} / \mathrm{R}$ is confirmed by the fact that in contexts where E-I constructions occur, a paraphrase of their original I-I meaning is possible:

$<$ LDIS $>$

(b) You probably don't know that a remarkably few were collected, to provide brass for armaments.

(b) You probably don't know that I wouldn't mind it staying open cos I'm a bit hot. $<\mathrm{X}>$

Finally, it is worth observing that, despite the spoken nature of both examples, actually in (3) was originally employed in a monologue, thus not addressing a proposition previously uttered by a specific interlocutor. This point will turn out to be of crucial importance in the ensuing analyses of this work.

\section{From I-I to E-I: introductory evidence from Mandarin}

From a methodological point of view, the bulk of recent approaches to (inter)subjectification generally aim at answering a fundamental question: Given the form-meaning pair L (lexeme) what changes did meaning $\mathrm{M}$ of $\mathrm{L}$ undergo? (Geeraerts, 1997). This question is at the core of the historical linguistic framework known as semasiology.

In semasiological studies, the form of L (its morphosyntactic and morphophonological properties) through time generally remains constant or undergoes only minor morphophonological changes. The main focus is thus on the development of polysemies within the same construction.

\footnotetext{
${ }^{6}$ For the reader's convenience I will label in square brackets all the contrastive examples of immediate and extended

intersubjectification of a construction: [L-S], [I-I], and [E-I].
}

Comment [AS16]: Geeraerts, 1997: Not in Refs.

$>>$ Added (highlighted in yellow). 
An example of semasiological reanalysis can be the chunk AS LONG AS meaning originally 'equal in length' with the added semantic connotation of 'equal in time' and the further one of 'provided that'. The same can be noted for even originally conveying 'evenly', then reanalysed with the additional connotation of 'unexpected member of set of alternatives' (Traugott $\&$ Dasher, 2002, p. 25; see also Brinton \& Traugott, 2005).

The semasiological model can be schematically represented as in (5) (from Traugott \& Dasher, 2002, p. 25):

$<$ LDIS $>$

(5)

$$
\mathrm{L} \rightarrow\left[\begin{array}{c}
\text { Form } \\
\mathrm{M}_{1}
\end{array}\right]>\mathrm{L} \rightarrow\left[\begin{array}{l}
\text { Form } \\
\mathrm{M}_{1}+\mathrm{M}_{2}
\end{array}\right]
$$

As can be observed from (5) above, along a semasiological cline of change, a lexeme (or construction or a chunk) $\mathrm{L}$ originally only conveys a single meaning $\mathrm{M}_{1}$. At a later stage of reanalysis, despite the fact that the original Form has remained the same - or has undergone only minor changes $-\mathrm{L}$ has now become polysemous, as it can now express an additional meaning $\mathrm{M}_{2}$. The scheme in (5) is a symbolic representation of semasiological change; it is then not specified which kind of cognitive or pragmatic mechanism is leading to the development of $\mathrm{M}_{2}$. Crucially, when a semasiological approach is concerned with diachronic phenomena of (inter)subjectification, the focus is on the cognitive construals and pragmatic motivations determining newly subjectified or intersubjectifed meaning(s) $\mathrm{M}_{\mathrm{n}}$ of a construction or lexeme $\mathrm{L}$. This latter domain of inquiry constitutes one of the main models of analysis in the present study. In other words, we will focus on the semasiological reanalysis of a construction or lexeme $\mathrm{L}$ when motivated by cognitive and pragmatic construals of (inter)subjectivity (cf. Traugott \& Trousdale, 2013, on the intersections between semasiology and constructional change).

In the next section, I will provide a corpus-illustrated (cf. Tummers et al., 2005, p. 235) case of semasiological change from I-I to E-I about the Mandarin construction 干嘛 gànma 'what (are you) doing'. The term 'corpus-illustrated' refers to a corpus technique frequently adopted in historical linguistics. As the term suggests, it is generally used to illustrate when new stages of semantic or grammatical reanalysis are attested as a new construction first appears in a diachronic corpus (influential accounts based on corpus-illustrated techniques can be found in Traugott, 1989, 1999, 2003, 2010, 2012; Bybee, Perkins, \& Pagliuca, 1994; Hopper \& Traugott, 2003; and others). 
The main purpose of this introductory study will be to give some preliminary evidence regarding the diachronic continuum from I-I to E-I in languages other than English. Two ensuing corpusbased studies will then be focused on the two chunks [you don't want to $\mathrm{X}]^{7}$ and believe it or not in American English. All the analyses that will be provided in this work are mainly grounded in the frameworks of chunking (cf. Newell, 1990; Bybee, 2010) and invited inferencing theory (IIT) (Traugott, 1999, 2002, 2003, 2010, 2012). More specifically, the present study aligns with the view that "the underlying cognitive basis for morphosyntax and its hierarchical organization is the chunking of sequential experiences” which occurs mainly with repetition (Newell, 1990; Haiman, 1994; Bybee, 2003, 2010, p. 34). This notion applies to morphemes, words, and larger formulaic patterns and is centred on semantic-pragmatic reanalyses due to newly acquired meaning in context. When two or more smaller chunks occur together with some degree of frequency, then a larger chunk containing the smaller ones is formed. Frequently used phrases and newly formed chunks are processed holistically, which implies "that rather than accessing each unit separately and putting them in a construction, a whole sequence is accessed at once”. This does not entail that the parts of a chunk are not identifiable, "but continued access as a whole contributes to the weakening of their identifiability and thus the analyzability and/or compositionality of the whole expression” (cf. Bybee, 2010, p. 52). ${ }^{8}$

\subsection{FROM I-I TO E-I: THE 干嘛 GÀNMA CONSTRUCTION IN MANDARIN}

Our introductory study addresses the Mandarin construction 干嘛 gànma, composed by the verb 干 gàn 'to do' and the end-sentence emphatic modal particle 嘛 $\mathrm{ma}^{9}$ (cf. Lü, 1999; Shen, 2003; Qiang, 2007, 2008). This chunk is the result of a phonetic and morphological reduction from the construct 干什么 gàn shénme 'doing what' which, despite the absence of a second person pronoun, can be translated with expression What are you doing?

The first occurrence of 干嘛 gànma occurring in the diachronic section of the PKU-CCLCORPUS (Peking Center for Chinese Linguistics Corpus) ${ }^{10}$ is from the 清 Qing dynasty (16441911). This first usage presents a comparatively less-subjective (rather literal) reading:

\footnotetext{
${ }^{7}$ The brackets are meant to bound the construction including an X slot (cf. Goldberg, 1995).

${ }^{8}$ Analyzability and compositionality will be formally introduced in the next subsection.

${ }^{9}$ It can alternatively be transcribed with the final interrogative particle 吗 $m a$ or the morpheme 么 $m e$.

${ }^{10}$ Project website: <http://ccl.pku.edu.cn:8080/ccl_corpus/index.jsp?dir=xiandai> (last accessed 3 March 2014).
}

Comment [AS17]: Traugott, ... 2002: Not in Refs.

>> Change into Traugott 2003, 2010, 2012; Traugott \& Dasher 2002

Comment [AS18]: 3.2.: There is no Section 3.1 .

>> Change into section 3.1

Comment [AS19]: Footnote 10: The link doesn't work for us.

>> I have tried and still works for me (opena access). 
$<$ LDIS $>$

[L-S]

(6) 你 来 京 么? (Qīng 1644-1911-Guānchăng xiànxíngjì [PKU-CCL])

nǐ lái jīng gàn me?

you come Beijing do what/INT-PART ${ }^{11}$

'What are you doing here in Beijing?'

$<X>$

During the 民国 Mínguó period (1912-1949), 干嘛 gànma undergoes a semantic-pragmatic and grammatical reanalysis as it starts to appear in the corpus in a preverbal position with a new rhetorical interrogative function, paraphrasable as Why would you P? :

$<$ LDIS $>$

[I-I]

$$
\begin{array}{llll}
\text { 你 那 院 } & \text { 里 衣食 } & \text { 丰足, 干吗 在 这里 受穷[...]? } \\
\text { nǐ nà yuàn } & \text { lǐ yīshí } & \text { fēngzú , gànma zài zhèlǐ shòuqióng }
\end{array}
$$

you that courtyard in clothes\&food abundant ganma stay here be-poor

'You would have plenty of clothes and food in that courtyard, why are you staying here and living in poverty?'

(Mínguó 1912-1949 - Gǔjīnqínghǎi [PKU-CCL])

In (7) above a new I-I polysemy has been added to the literal meaning of 干嘛 gànma. In fact SP/W considers a situation from AD/R's viewpoint with a new idiomatic meaning added to the construction. In other words, (7) is here more idiomatic than (6) in that SP/W is not literally asking $\mathrm{AD} / \mathrm{R}$ what s/he is doing, but rather rhetorically asking him/her WHAT IS THE POINT of doing it. From a semasiological perspective, the new rhetoric meaning emerging from (7) corresponds to a crystallized invited inference (cf. Traugott \& Dasher, 2002, p. 16) or generalized conversational implicature (cf. Levinson, 1995) which is now directly identifiable with the preverbal construction 干嘛 ganma, independently from the context in which it is used. That is to say, the rhetorical interrogative function of (7) corresponds to the generalization of a conversational implicature that prior to this stage could only arise in context, while now it is inherently part of the semantic-

Comment [AS20]: Levinson, 1995: Not in Refs.

>> Change into Levinson, 2000 (new reference added, highlighted in yello)

\footnotetext{
${ }^{11}$ Interrogative particle.
} 
pragmatic meaning of the construction. The comparatively higher degree of reanalysis of (7) with respect to (6) is also due to a lower degree of COMPOSITIONALITY (Langacker, 1987; Bybee, 2010) and ANALYZABILITY (Langacker, 1987). The former has to do with the semantics of a construction and refers to the degree of predictability of the meaning of the whole from the meaning of the component parts (cf. Bybee, 2010, p. 45). The latter is grammatical notion and regards the recognition of the contribution that each component makes to the composite conceptualization (cf. Langacker, 1987, p. 292). Namely, (6) is comparatively more compositional as the verb 干 gàn 'to do/to act' and its object (什)么 (shén)me 'what' literally refer to some action or activity to be carried out by an actor. On the other hand, the preverbal chunk 干嘛 gànmà in (7) is less compositional as it does not describe an actor's action/activity but rather challenges the plausibility of his/her choice. Similarly, (6) is more analyzable than (7), as in the former case 干嘛 gànmà grammatically corresponds to the predicate ${ }^{12}$ of the sentence, while in the latter it occurs in a preverbal position functioning as a mood operator (it can be replaced with 为什么 wèishénme 'why'). Finally, (6) and (7) correspond to two different speech acts, as in the former case SP/W's presumption of optimal relevance (cf. Sperber \& Wilson, 1995) is to genuinely understand the reason why AD/R 'has come to Beijing'. Quite differently, (7) corresponds to a face-threatening act (cf. Brown \& Levinson, 1987) as SP/W pragmatically aims at criticizing AD/R's decision.

Interestingly, since the 1950s, 干嘛 gànma starts to appear in declarative sentences (before then it could only be used in interrogatives) and with first person (generally plural) pronouns. Consider example (8) below:

$<$ LDIS $>$

[E-I]

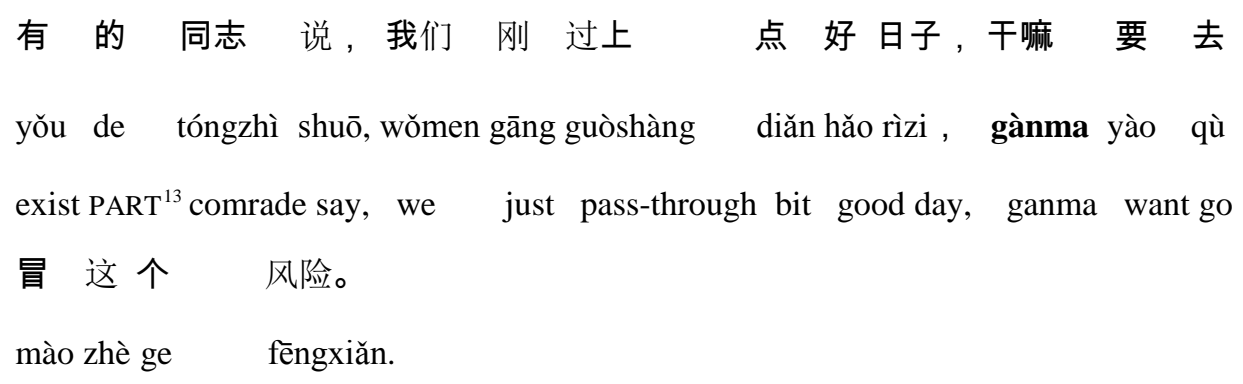

${ }^{12}$ In Chinese linguistics, the notion of predicate generally includes the following object or any other element occurring in a postverbal position.

${ }^{13}$ Structural particle. 
take this CLAS ${ }^{14}$ risk.

'Some comrades say, we've just had a decent day, we shouldn't go and take such a risk.'

(1995 - People's Daily [PKU-CCL])

$<\mathrm{X}>$

As can be noted from (8) above, due to a new E-I reanalysis, the chunk is now comparatively less compositional and analyzable than (7): the syntactic subject of 干嘛 gànma no longer obligatorily corresponds to a specific $\mathrm{AD} / \mathrm{R}$, the proposition occurs in the declarative mood, and the construction now functions as a preverbal deontic marker expressing negative mood, translatable as as anyone would agree, we shouldn't/mustn't $P$. The new semantic-pragmatic and grammatical reanalysis of the construction includes an assumed 3rdP who could indirectly confirm the good sense of SP/W's proposition and at this stage can be employed in monologues and written registers. From (7) to (8), we can observe a shift in profile from a more AD/R-oriented meaning (I-I) to a newer 3rdP-oriented one (E-I), as the construction has acquired a new social and indirect deixis.

4. From I-I to E-I: a complement to the existing models of analysis This is not the first study holding that intersubjectivity not only pertains to the speech participants engaging in a conversation not being necessarily 'immediate'. Nuyts $(2001,2012)$ characterizes intersubjectivity more broadly than the traditional I-I dimension, pointing out that intersubjective can be considered the SP/W's attempt to share the responsibility of an assertion. This approach is based on the semantic-pragmatic intersection between intersubjectivity and evidentiality, and inspired a number of works in modal epistemic and evidential studies (e.g., Cornillie, 2004, 2007; Tantucci, 2013, 2014b). An additional study worth mentioning is the one proposed by Narrog (2010, 2012), who first considers a possible further step of semantic reanalysis after the (I-I) one along the Traugottian cline of intersubjectification. ${ }^{15}$ He first points out that in the modal domain, other than subjectification (as increased orientation towards the speaker) and intersubjectification (as increased orientation towards the hearer), there seems to be a third tendency of change. The example he provides is from Coates (Narrog, 2010, p. 31; 2012, p. 36):

$<$ LDIS $>$

(9) I looked at some of my portraits and grotesque as they may be, they capture some aspects of reality.

(Coates, 1983, p. 135)

\footnotetext{
${ }^{14}$ Classifier.

${ }^{15}$ I label intersubjectification in the Traugottian sense as immediate-intersubjectification (I-I) in Section 2.1.
} 
$<\mathrm{X}>$

Narrog argues that the concessive usage of may in (9) is primarily intersubjective, as the SP/W seems to take into account a virtual objection or criticism by $\mathrm{AD} / \mathrm{R}$ and hence provides a counterargument to it. He further claims that, beyond this form of intersubjective meaning, may also syntactically functions as a binding-component supporting the textual coherence of the discourse. This phenomenon is what he defines as 'discourse orientation', which he considers a further stage of reanalysis after the well-known ones of subjectification and intersubjectification. Despite this remarkable intuition, a discourse-oriented reading is felicitous for ex-intersubjective constructions contributing to the overall coherence of the text or the discourse, but not as explicative for highly idiomatic chunks appearing in isolation. Consider the pair of the intersubjective idiom you got to be joking reported below:

$<$ LDIS $>$

[I-I]

(10) “Suppose you change your mind, and you want another baby sometime?” Anita's laughter is like a monkey’s mocking shriek. "You got to be joking! I mean, I love my kid and all, but one time giving birth is enough."

$\left(\right.$ COCA $^{16}$-Susan Volchok, 'Girl Talk’, 1993)

[E-I]

\section{(11) 'You gotta be joking!'}

[The thirteen dwarves are hurt on the ground after falling into a precipice in the ogres' cavern. All of a sudden, the huge carcass of a dead ogre falls right over them, at which point one dwarf utters (11).]

(Peter Jackson, The Hobbit, 2012)

$<\mathrm{X}>$

In (10), you got to be joking encodes what Tantucci (2013, 2014b) defines as immediate intersubjectivity, as it is exclusively addressed to a specific AD/R. SP/W speaks from AD/R's perspective and makes an assertion referring to how s/he imagines $\mathrm{AD} / \mathrm{R}$ 's stance to be in that particular context.

Quite differently, in (11), you gotta be joking functions as an E-I construction (cf. Tantucci, 2013, 2014b) as the intersubjective construal of the chunk is not limited to the speech event and not exclusively addressed to a specific $\mathrm{AD} / \mathrm{R}$. With this performative expression, one of the dwarves expresses a feeling of incredulity towards an unexpected event, rather replying to a previous utterance. Additionally, the construction is uttered in the form of a monologue, with the assumption

\footnotetext{
${ }^{16}$ Project home page: <http://corpus.byu.edu/coca/>.
} 
that anyone would agree and sympathize with it: his companions (AD/R) together with any other member of society (3rdP). At this point of semasiological reanalysis, the second person pronoun you is not addressed to a specific single persona and the expression got to be joking is not a response to a statement previously made by an interlocutor. An ideal paraphrase of the expression in (11) would be as anyone would agree, this is impossible!

Intuitively, it would be strained to consider the highly intersubjectified form in (11) as a 'discourse-oriented' construction in Narrog's sense. It rather appears as a very idiomatic exclamation in isolation, completely detached from any ongoing discourse. The chunk in (11) is comparatively less compositional in that the holistic meaning this is impossible! is not directly inferable from the meaning of the separate components of the construction: you gotta be joking. It is similarly not highly analyzable in that the pronoun you has lost its original second person singular deixis and the reduced epistemic gotta is not referring to an animate subject. ${ }^{17}$

Back to Narrog's observation, the discourse-orientation of E-I constructions is indeed a most likely phenomenon as the latter frequently appears in monologues and in the written language. Nonetheless, it needs to be observed that the primary meaning of E-I constructions such as (10-11) is the assumed awareness of a 3rdP, rather than the attempt to bind discourse coherence. To explain, the binding function of may in (9) is undeniable; however, the fundamental meaning of the chunk is again the assumed encoding of a 3rdP as an assumed external interlocutor: grotesque as they may be (considered by someone), they capture some aspect of reality. Even in this more discourseoriented usage, the core meaning of may is the assumed 3rdP as an inherent element of the construction. That being said, it is a fact that E-I constructions often do show a new discourseorientation, not present at previous I-I stages of reanalysis. ${ }^{18}$

To conclude this section, I propose that extended-intersubjectivity is to be intended as a new 3rdP-oriented reanalysis of an original I-I counterpart. E-I is characterized by a comparatively lower degree of analyzability, compositionality, and a most likely - though not absolute - new discourseorientation. Drawing on Traugott's cline, I add a further E-I stage of intersubjectification whereby 3rdP inherently becomes a semantic element of the construction. Below, I quote Traugott's (2010, p. 44) original pathway of change from subjectification to intersubjectification:

$<\mathrm{NL}>$

\footnotetext{
${ }^{17}$ On a scale, the degree of analyzability of a construction is often indirectly proportional to its degree of schematicity and abstraction (cf. Croft \& Cruse, 2004; Trousdale, 2012). On the other hand, the present work is centred on semasiological phenomena of semantic-pragmatic change whereby formal reduction and atomicity are not fundamental - nor the only - criteria for judging the degree of semantic reanalysis of a construction (cf. Traugott \& Dasher, 2002, p. 25).

${ }^{18}$ See data from the survey of believe it or not in Section 5.3.
} 
a. meanings are recruited by the speaker to encode and regulate attitudes and beliefs (subjectification), and,

b. once subjectified, may be recruited to encode meanings centred on the addressee (intersubjectification).

$<\mathrm{X}>$

The basic cline of intersubjectification she provides is the following (Traugott, 2010, p. 35):

$<$ LDIS $>$

(12) non-/less subjective $>$ subjective $>$ intersubjective $<\mathrm{X}>$

Here I then provide my implementation of Traugott's unidirectional framework:

$<\mathrm{NL}>$

a. meanings are recruited by the speaker to encode and regulate attitudes and beliefs (subjectification), and,

b. once subjectified, may be recruited to encode meanings centred on the addressee (immediate intersubjectification),

c. once 'immediately intersubjectified', may be recruited to encode meanings taking into account the addressee as well as a generic third party in society or society as a whole (extended intersubjectification).

$<\mathrm{X}>$

With an extended version of her original intersubjectification cline:

$<$ LDIS $>$

(13) non-/less subjective $>$ subjective $>$ immediate-intersubjective $>$ extended-intersubjective. $<\mathrm{X}>$

The distinction between I-I and E-I is not confined to the linguistic domain. It rather tackles the broader opposition in cognitive psychology between a neurologically triggered form of 'simulation theory' (ST) of mindreading from a more generalised and folk-psychologically acquired 'theorytheory' (TT) of others' minds (cf. Goldman, 2006). While the former holds that a conceptualizer directly simulates in his/her own mind the physical, emotional, or epistemic status of another individual, the latter has to do with an inferential and 'information-based' process of mindreading, not necessarily bound to the neurological simulation of another mind's condition. In fact, if a semasiological continuum can be attested from a more direct form of mindreading to a more extended and generalized one, it would then be possible to count on new evidence confirming the ST and TT are not mutually exclusive, but in diachronic connection with one another. 


\section{The intersubjectification of [you don't want $\mathrm{X}$ ] and believe it or not in American English}

In this section I will provide two detailed corpus-based surveys about the tendency towards E-I of the constructions [you don't want $\mathrm{X}$ ] and believe it or not in American English (AE). The aim of these two case studies will be to support the hypothesis of a semasiological continuum from I-I to E-I on a quantitative level.

\subsection{THE INTERSUBJECTIFICATION OF [you don't want X]: ANALYSIS CRITERIA AND SCOPE OF ENQUIRY}

In this section I will discuss the criteria which have been adopted to analyze quantitatively and qualitatively the semasiological reanalysis of [you don't want X] in AE. More specifically, I will focus on the progressive I-I and E-I process of change of [you don't want X] from 1810 up to 1920 in the COHA, ${ }^{19}$ a 400 million word diachronic corpus of American English.

The methodology I adopted for this survey is based on the frameworks of chunking (Bybee, 2010) and invited inferencing theory (Traugott, 1999, 2002, 2003, 2010, 2012), which both hold that along a process of semantic-pragmatic (and potentially grammatical) reanalysis, frequently made inferences from the context become part of the meaning of a chunk: "This suggests no clear divide between aspects of the meaning that are derivable from context and those that are inherent to the lexical item or construction” (Ibid.; see also Traugott, 2003, 2010, 2012). In other words, new constructions or formulaic patterns are specific exemplars of more general existing constructions "that take on new pragmatic implications, meanings due to their use in particular contexts" (Bybee, 2010, p. 28).

A famous example which illustrates this phenomenon is the so-called 'WXDY?' construction What's this fly doing in my soup? (cf. Fillmore \& Kay, 1999). The usual interpretation of What is $X$ doing $Y$ ? has to do with surprise at incongruity accompanied by more than a hint of disapproval. Nonetheless, because it is syntactically indistinct from the construction from which it arose (a what question with do in the progressive), the chunk is polysemous, as it gives licence to interpret it as a literal question about what the fly is doing: "Interestingly, there is nothing in the form which explicitly suggests a meaning of incongruity, but the strong implication is nonetheless there” (Bybee, 2010, p. 28). Concerning idiomatic constructions and chunking patterns as such, the fundamental role played by the repetition of invited inferencing and pragmatic implications in context is generally agreed to be the primary trigger of new polysemies. Accordingly, the present study will provide an operational framework centred on the diachronic reduction of analyzability

\footnotetext{
${ }^{19}$ Project website: <http://corpus.byu.edu/coca/> (last accessed 3 March 2014).
} 
and compositionality of [you don't want X] (the progressive loss of literal meaning) rather than focusing on hierarchical networks and specific nodes having to do with the class of items (i.e., NPs, VPs, predicate types) co-occurring within the chunk. As for the aforementioned 'WXDY?' construction, even in the case of [you don't want X] I hold that the main element prompting the semantic reanalysis of the construction will be the pragmatic employment of the whole pattern (i.e., as a bare assertion rather than occurring in questions or relative clauses) independently from the class of items it will appear with. In other words, in the present survey we will not focus on a varying distribution of word classes in the $\mathrm{X}$ slot of the [you don't want $\mathrm{X}]$ construction through time. The reason for this is duplex:

$<\mathrm{NL}>$

a. According to IIT and diachronic phenomena of chunking, the internal occurrence of some word classes rather than others (i.e., NP rather than VP in the X slot of [you don't want X]) does not always represent a determining factor for the semantic-pragmatic and/or grammatical reanalysis of a construction. What is most crucial is rather the distribution and the usage of the chunk in context. This entails that the chunk itself will progressively turn into a new unit, the internal constituency of which will be characterized by a progressive diminishing of analyzability and compositionality.

b. Corpus-driven evidence from the present survey does not indicate a different distribution of word classes in the $\mathrm{X}$ slot at different stages of semasiological change.

$<\mathrm{X}>$

For this reason, what will we be looking for is a new intersubjectified (both I-I and E-I) employment of the whole chunk on a pragmatic-semantic level, which can be formally and statistically distinguished from less reanalysed (more literal) ones.

To achieve this, it was necessary to divide the usages of [you don't want $\mathrm{X}$ ] into three main categories: less-subjective, immediate-intersubjective, and extended-intersubjective. As the original semantics of the chunk is already oriented towards the $\mathrm{AD} / \mathrm{R}$, the cline does not include a marked subjectified stage, but rather a direct shift from L-S to I-I. The formal criteria appearing in Table 1 have been established due to corpus-based reduction of analyzability and compositionality of the chunk (see Section 3.2 for more details) as well as determined by corpus-driven analysis of the data:

Comment [AS23]: see Section 3.2 for more details: Please check crossreference.

>> Change into 3.1 
L-S - old information (AD/R already knows about $P$ )

- occurring in questions, hypotheticals, or as a confirmation of the state of affairs related to $A D / R$ (in the latter case often introduced by so or that).

- question asked or hypothesis made to a specific $A D / R$

- you is addressed to a specific $A D / R$

I-I - new information ( $A D / R$ does not know about $P$ )

- used as an assertive speech act

- presuppositional meaning based on the specific knowledge of $A D / R$

- you is addressed to a specific $A D / R$

- you cannot be replaced with one

E-I - new information (AD/R does not know about $P)$

- used as an assertive speech act

- presuppositional meaning addressing $A D / R$ as well as a general $3 r d P$

- you is addressed to $A D / R$ and to 'anyone else' in his/her place

- you can be replaced with one

TABLE 1. Criteria adopted for the analysis of the intersubjectification of [you don't want X]

From the three examples below we can first learn how to apply the criteria in Table 1 in order to distinguish between L-S, I-I, and E-I usages:

$<$ LDIS $>$

[L-S]

(14) I've been thinkin', if you don't want to have anything to do with him, we betta go ouaselves.

(COHA _ James Fenimore Cooper, Oak Openings, 1848)

(15) You don't want to be married. You are too young - you are.

(COHA -May Agnes Fleming, A Terrible Secret, 1874)

[E-I]

(16) But, after fasting so long you don't want to eat too much at first.

(COHA -H. Irving Hancock, Dick \& Co. Start Things Moving, 1911) $<\mathrm{X}>$

Following the criteria given in Table 1, the three examples above respectively correspond to instances of L-S, I-I, and E-I. To explain, in (14) [you don't want X] is labelled as L-S as it appears in a hypothetical construction, objectively - or rather, less-subjectively - reporting in the protasis a piece of old information, some state of affairs SP/W and AD/R are both aware of: you don't want to 
have anything to do with him. Despite the second person pronoun you and the proposition referring specifically to $A D / R$, the construction has not idiomatically acquired an AD/R's oriented meaning as it does not constitute an independent assertive speech act.

Quite differently, the chunk in (15) has intersubjectified as an I-I construction. It conveys new information to $\mathrm{AD} / \mathrm{R}$ (the latter is told a proposition s/he was not aware of); it functions syntactically as a main clause and pragmatically as an assertive speech act. Additionally, it presupposes previous knowledge of $\mathrm{AD} / \mathrm{R}$ as a specific persona with particular feelings and beliefs. At this point, a certain degree of idiomaticity is already encoded in the proposition, as the AD/R is literally informed about what s/he (does not)want(s). This last point is fundamental as - at this stage of reanalysis - the second person pronoun you in (15) cannot be substituted with one, precisely due to SP/W's immediate awareness of $\mathrm{AD} / \mathrm{R}$ in his/her specificity

Finally, a new process of constructionalization (cf. Traugott \& Trousdale, 2013) occurs in the E-I reanalysis of (16). To explain, similar to (15), here [you don't want X] is also employed assertively. However, it now conveys a more generic awareness of the AD/R (it could be directed to anyone) as well as an assumed 3rdP, who is supposed to react exactly as the AD/R would: after fasting so long you (as anyone else) don't want to eat too much at first. In other words, the shift from I-I to E-I corresponds to a reanalysis from a personal meaning (oriented towards the AD/R), to a social one (extended to a generic 3rdP). The mismatch between I-I and E-I is easily tested by substituting you with (no-)one (see Table 1):

$<$ LDIS $>$

[I-I]

(15) (a) *No one wants to be married. You are too young - you are.

[E-I]

(16) (a) But, after fasting so long no one wants to eat too much at first. $<\mathrm{X}>$

It is important to point out that I-I and E-I here correspond to two different speech acts: while in (15) SP/W's presumption of optimal relevance (cf. Sperber \& Wilson, 1995, pp. 266-278) is to express his/her knowledge and understanding of a specific addressee, on the other hand, the optimal relevance in (16) is presumed to be achieved by conveying a social meaning, a theory of mind of how anyone would react in that specific context. As I pointed out in Section 2.4, the semasiological reanalysis from I-I to E-I is characterized by a reduction of the analyzability and compositionality of the chunk. In the former case, the personal pronoun you has lost its second person deixis, now referring more generally to anyone. Similarly, the chunk is less compositional in that the emerging meaning of the construction is felicitously paraphrased as no-one wants and does not refer anymore to a specific will on behalf of the $\mathrm{AD} / \mathrm{R}$. 
One last point that needs to be made is that the pronoun you itself corresponds to a construction undergoing a process of semantic-pragmatic reanalysis. This is due to the loss of a L-S second person deixis. Nonetheless, the main focus of this survey lays on the semasiological change of the whole chunk [you don't want X] as an idiomatic, holistic function of E-I. It is a fact that E-I idiomatic usages of the chunk [you don't want X] such as the one in (16) are not present in various non-Germanic languages (i.e., Romance, Sinitic, and others).

\subsection{THE INTERSUBJECTIFICATION OF [you don't want X] IN AE}

In this section I will provide corpus-based evidence from the COHA related to a 120 -year period from 1810 up to the end of $1920 .{ }^{20}$ Based on the criteria given in Table 1 , I analyzed all the 1,166 occurrences of the chunk year by year, dividing the usages once again in L-S, I-I, and E-I as given in Table 2.

$<$ Table 2 about here $>$

\begin{tabular}{ccccccccccccc} 
& 1810 & 1820 & 1830 & 1840 & 1850 & 1860 & 1870 & 1880 & 1890 & 1900 & 1910 & 1920 \\
\cline { 2 - 11 } L-S & 2 & 4 & 9 & 27 & 31 & 62 & 64 & 89 & 79 & 119 & 150 & 177 \\
I-I & 0 & 0 & 2 & 7 & 6 & 12 & 19 & 27 & 24 & 41 & 50 & 58 \\
E-I & 0 & 0 & 0 & 1 & 3 & 3 & 10 & 10 & 12 & 16 & 23 & 33
\end{tabular}

TABLE 2. Raw frequency of L-S, I-I, and E-I usages of [you don't want X] in the COHA from 1810 to 1910

Then I first calculated the normalized frequency (NF) per decade of all the intersubjectified usages of the chunk. This was done in order to find out if a general process of intersubjectification did actually occur during the period I considered. The result of this calculation is reported in Figure 3.

$<$ Figure 3 about here $>$

\footnotetext{
${ }^{20}$ This choice is corpus-driven. Not many usages are found at the beginning of the nineteenth century (when the COHA starts); as a result, it was necessary to take into account a large time span to observe statistically significant results.
} 


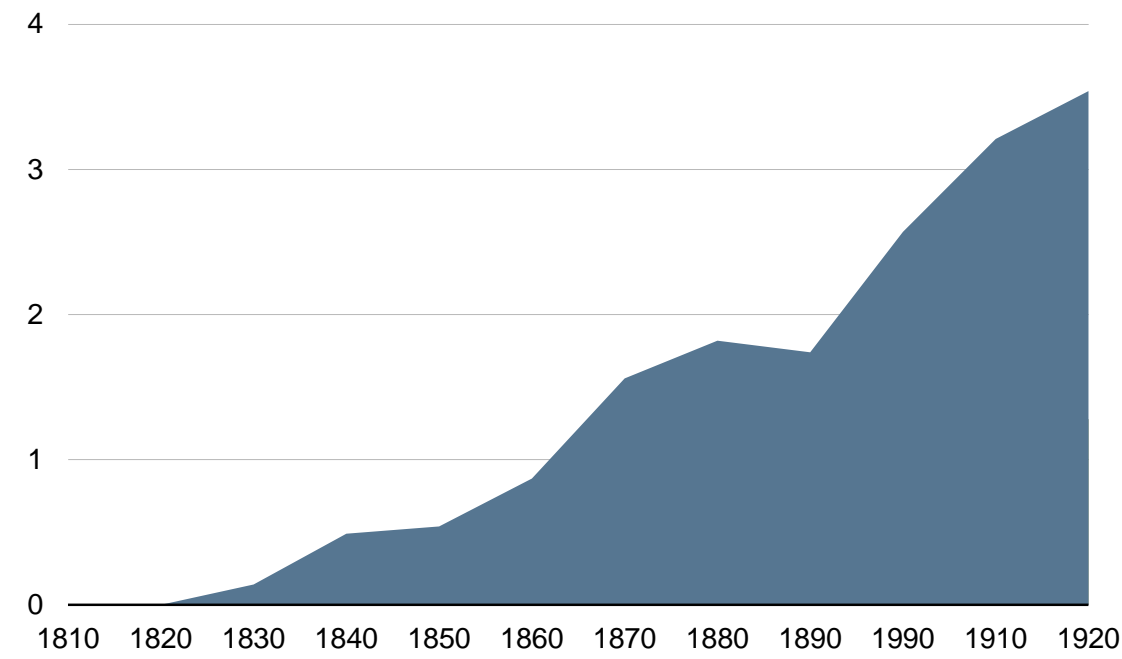

Fig. 3. NF per decade of intersubjectified usages of [you don't want X].

On the $x$-axis In Figure 3 are reported the twelve decades I focused on, whereas the $y$-axis indicates the frequency per million words related to each corpus (which differ in size in every decade). As can immediately be noticed, there is a dramatic increase of intersubjectified usages of the chunk starting from 1830. This increasing process of reanalysis is statistically significant when comparing the intersubjectification of the chunk between 1810 and 1860 with the remaining six decades $(p<.0001)$.

Subsequently, I calculated the percentage frequency of intersubjectified usages (including both types I-I and E-I) with respect to the overall occurrences of the chunk found in every decade from 1810 to 1920 . This calculus was made so as to represent the increasing frequency of the intersubjectified employment of the chunk in comparison with L-S usages, as exemplified in Figure 4.

$<$ Figure 4 about here $>$ 
50

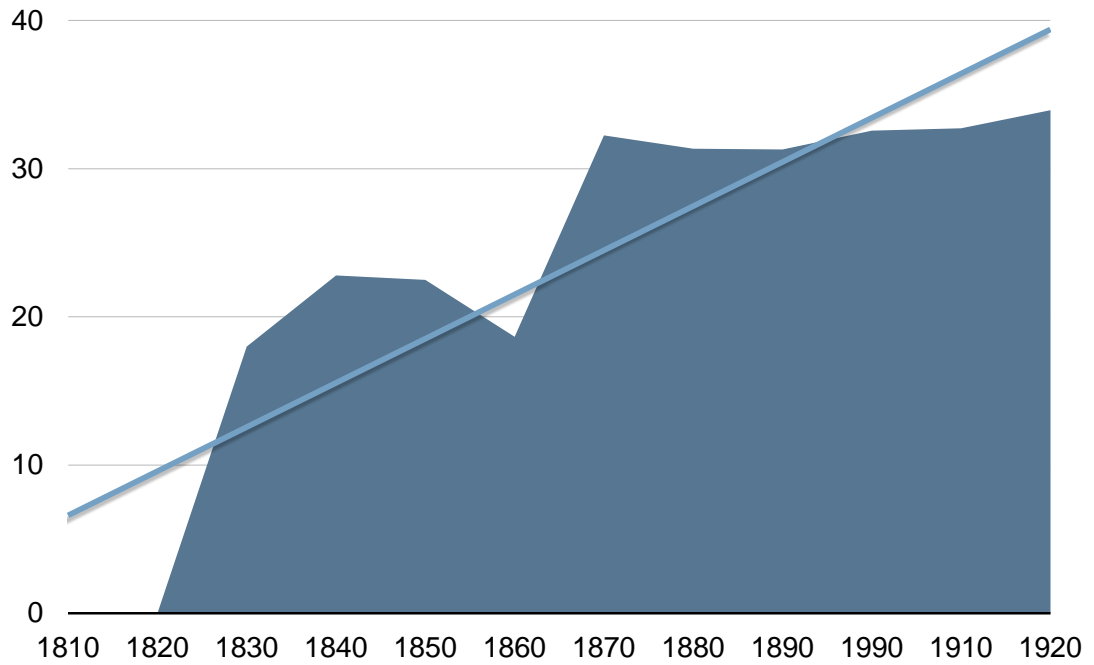

Fig. 4. Percentage of intersubjectified usage [you don't want $\mathrm{X}$ ] with respect to the overall employment of the chunk.

The $y$-axis in Figure 4 indicates the percentage distribution of intersubjectified usages of [you don't want to $\mathrm{X}$ ] with respect to the overall employment of the chunk in each decade from 1810 to 1920 . As can be seen, apart from an isolated drop in 1860, the combined frequency of E-I and I-I usages increases progressively throughout the century, from 18\% in the year 1830 to 33.95\% at the end of 1910. The remarkable increase of the intersubjectified employment of the chunk is also more schematically represented by the transverse trend-line encompassing the whole period. ${ }^{21}$

Finally, I calculated the percentage of the NF of E-I usages with respect to the I-I employment of the construction. The aim of this calculus was to see whether the frequency of E-I (the earliest usage dates back to 1840) diachronically increased significantly in comparison with its I-I counterpart. The result of this analysis is given in Figure 5.

\section{$<$ Figure 5 ABOUT HERE $>$}

\footnotetext{
${ }^{21}$ In statistics, trend-line calculation (which can be automatically obtained in most of the graph-editing software available) is an approach for modelling the average relationship between a scalar dependent variable $y$ and one or more explanatory variables denoted $x$ (cf. Cohen, Cohen, West, \& Aiken, 2003).
} 


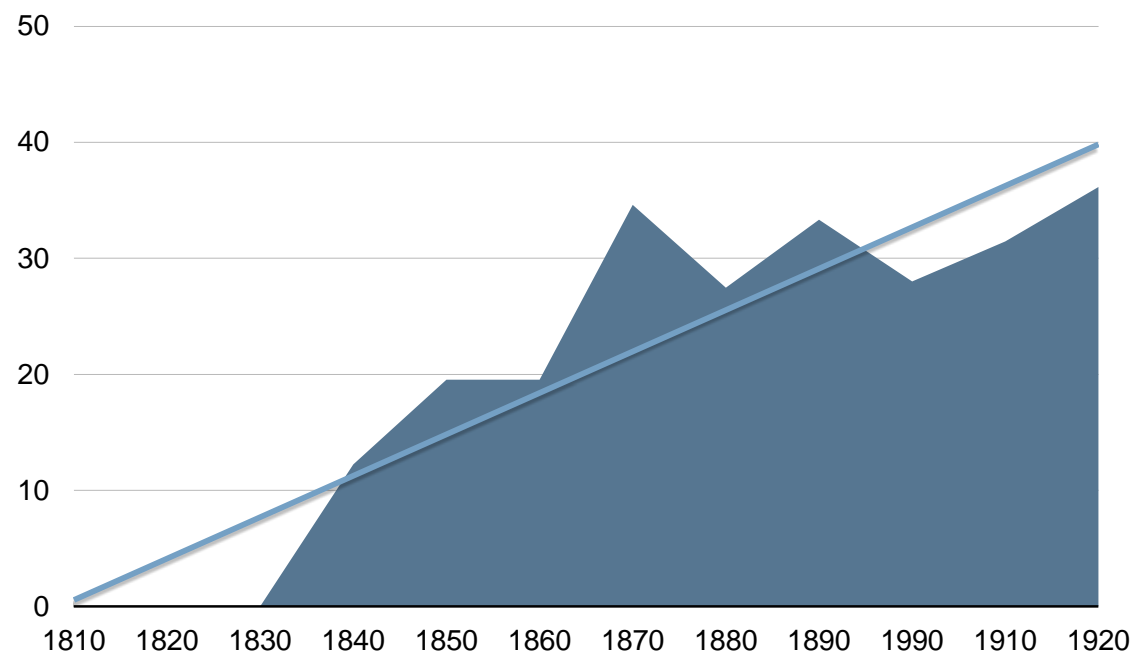

Fig. 5. Percentage of E-I NF [you don't want X] with respect to the (E-I+I-I) NF the chunk.

Despite the percentage increase of the NF of E-I usages in Figure 5, to verify the statistical significance of this graph $(p<.01)$ it was necessary to compare the two time spans 1810-1860 and 1870-1920 by entering in a log-likelihood contingency table the NF of E-I usages from 1810 to 1860, the NF of all intersubjectified usages from 1810 to 1860, the NF of E-I usages from 1870 to 1920, and the NF of all intersubjectified usages from 1870 to 1920 (for a detailed comparison of the log-likelihood and chi-squared statistics, see Rayson, Berridge, \& Francis, 2004).

Based on the results provided above, there are a few conclusions which can be drawn:

$<\mathrm{NL}>$

a. [you don't want $\mathrm{X}$ ] significantly underwent a process of intersubjectification.

b. E-I usages of the chunk significantly increased throughout the period considered.

c. The increased frequency of E-I usages occurred after an earlier development of I-I functions of the chunk.

$<\mathrm{X}>$

The semasiological change from L-S to I-I to E-I can be better comprehended through the analysis of the five examples below:

$<$ LDIS $>$

[L-S]

(17) What's the reason you don't want a black coat? tell me directly.

(COHA - ‘Tudor’s Life of James Otis’, 1823)

[L-S]

(18) You don't want to see me, boy, do you? 
$[\mathrm{L}-\mathrm{S} / \mathrm{I}-\mathrm{I}]^{22}$

(19) $[\ldots]$ you don't want cash for it surely.

(COHA - 'Young’s Chronicles of Massachusetts', 1846)

[I-I]

(20) [...] but you don't want such a piece of property, Lizzie.

(COHA -Susan Warner, Hills of the Shatemuc, 1852)

[E-I]

(21) The tomato appears well on the table; but you don't want to ask its origin.

(COHA -Charles Dudley Warner, My Summer in a Garden, 1870)

$<\mathrm{X}>$

Still based on the criteria provided in Table 1, the five examples above can give us a specific idea of the I-I and E-I process of the chunk [you don't want X] and the gradience among the different usages of this construction.

To begin with, (17) is beyond doubt an example of L-S usage. The construction appears in a subordinate clause, it is not assertive and refers back to a piece of old information. The next usage in (18) is still a form of L-S in that it is still perfectly analyzable and compositional, still communicating a piece of old information (the $\mathrm{AD} / \mathrm{R}$ is told about something s/he already knows). However, in this case the construction does not appear in an embedded clause, but is rather employed as a request of confirmation of a previous state of affairs in the form of a rhetorical question: [you don't want X, do you?]. This construction occurs extremely frequently in the COHA as it represents a bridging function from a non-assertive to an assertive stance. In fact, the old piece of information is expressed as a form of inference or assumption rather than an absolute state of affairs. In a similar fashion, (19) constitutes the last L-S stage of [you don't want X]. The pragmatic function of you don't want cash for it surely in (19) is quite similar to the chunk in (18), as it constitutes an inference regarding a piece of old information. What differs now is that the chunk is uttered in the declarative mood, no longer in the form of a question. Nonetheless, (19) cannot be considered fully assertive nor idiomatic. This is due to the presence of surely, here mitigating the assertive force of the utterance, and still marking it as a form of old information. ${ }^{23}$

\footnotetext{
${ }^{22}$ Half-way stage between less and immediate intersubjectivity.

${ }^{23}$ It is important to bear in mind here that the inferential meaning in (18-19) is literally posited. Both usages cannot be considered intersubjectified, as (inter)subjectification involves newly added meanings to the literal reading of a construction (see Section 3).
} 
Crucially, in (20) we have now a proper instance of I-I, whereby SP/W conveys new information to $\mathrm{AD} / \mathrm{R}$ in the form of an assertion (the $\mathrm{AD} / \mathrm{R}$ is told something $\mathrm{s} / \mathrm{he}$ did not know about). Different from (17-18-19), AD/R is here informed about what does (not) she want(s). The chunk is then less compositional as SP/W is not describing objectively a state of affair - as the separate elements of the construction would semantically suggest - but rather informing AD/R of something new, conveying an additional idiomatic meaning that was not present in (17-18-19).

Finally, in (21) [you don't want X] functions as an E-I construction. The chunk is assertive and conveys new information to a higher degree than (20): it cannot co-occur with the DM as you know. In addition, it is no longer oriented towards a specific $\mathrm{AD} / \mathrm{R}$, but can be uttered in the presence of anyone, in monologues or in the written language. The utterance is now characterized by a new 3rdP orientation, whereby no one would ask the origin of the tomato on the table. It is also less analyzable, as the second person pronoun you has loss its original deictic orientation, acquiring now a more social meaning (it can be formally substituted with (no) one).

To exemplify the intersubjectification process from (17) to (21) I drew a diachronic semantic map (cf. Anderson, 1986; Heine, 1992; Van der Auwera \& Plungian, 1998; Croft, 2001; Haspelmath, 2003) including most of the criteria I adopted for my analysis (see Figure 6).

$<$ Figure 6 about here $>$

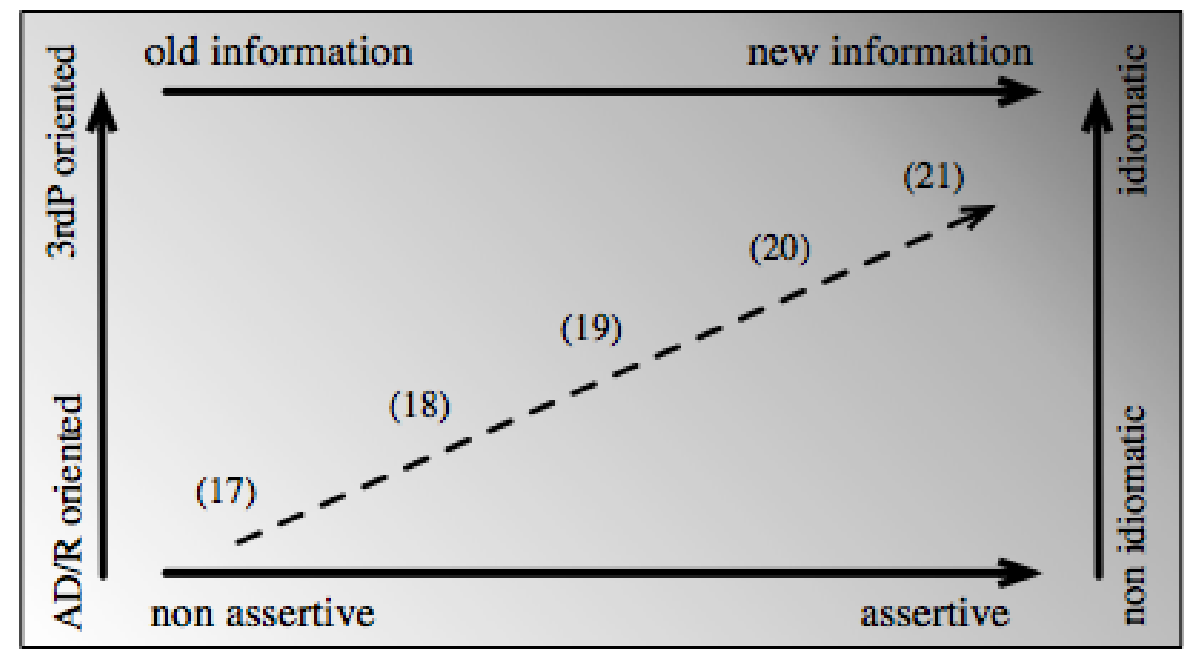

Fig. 6. Diachronic semantic map of the intersubjectification process of [you don't want X].

As schematically exemplified in Figure 6, the four main factors determining the immediate and extended intersubjectification of [you don't want X] are ASSERTIVITY, IDIOMATICITY, INFORMATION STATUS, and PERSONA'S ORIENTATION. As can be observed from the dotted line going 
from the L-S usage in (17) to the ultimately reanalysed E-I usage in (21), all four features in the map increase progressively, contributing to the semantic-pragmatic and grammatical reanalysis of the chunk. The construction in fact becomes increasingly more assertive, it conveys more and more prominently new information, it increases in its idiomaticity, and it shifts from an AD/R-oriented meaning a more 3rdP oriented one.

It is important to realize that the initial $\mathrm{AD} / \mathrm{R}$ orientation of (17-18) is simply due to the objective - or less-subjective - meaning of the chunk, whereby the second person pronoun you conveys semantically its original meaning: a specific deictic reference to the $A D / R$. It is only in the I-I example (20) that the construction acquires a more idiomatic AD/R orientation, as SP/W informs $\mathrm{AD} / \mathrm{R}$ about what she wants as a piece of new information.

\subsection{THE I-I AND E-I OF believe it or not IN AE}

The present study is a corpus-based analysis of all the occurrences of the chunk believe it or not in the COHA across 160 years time from 1810 up to $1960 .{ }^{24}$ As in the case of [you don't want X], the main aim of this survey is to find further empirical confirmation of the semasiological continuum from I-I to E-I, and thus from a more specific form of mindreading to a more generalized one. Adopting the same methodology given in Section 3.1, the usages of believe it or not have been divided into less-subjective, immediate-intersubjective, and extended-intersubjective). All the corpus-driven criteria (both syntactic and semantic-pragmatic) that have been adopted in this

Comment [AS28]: up to 1960: Again, should this be "up to the end of the 1960s"?

$>>$ Change into 'up to the end of the 1960s'

Comment [AS29]: Section 3.1; There is no Section 3.1 .

>> Section 3.1 now given.

\footnotetext{
${ }^{24}$ Similar to the previous survey, this choice is also corpus-driven. Not many usages are found at the beginning of the nineteenth century (when the COHA starts). For this reason it was necessary to take into account a large time span to statistically observe some significant results.
} 


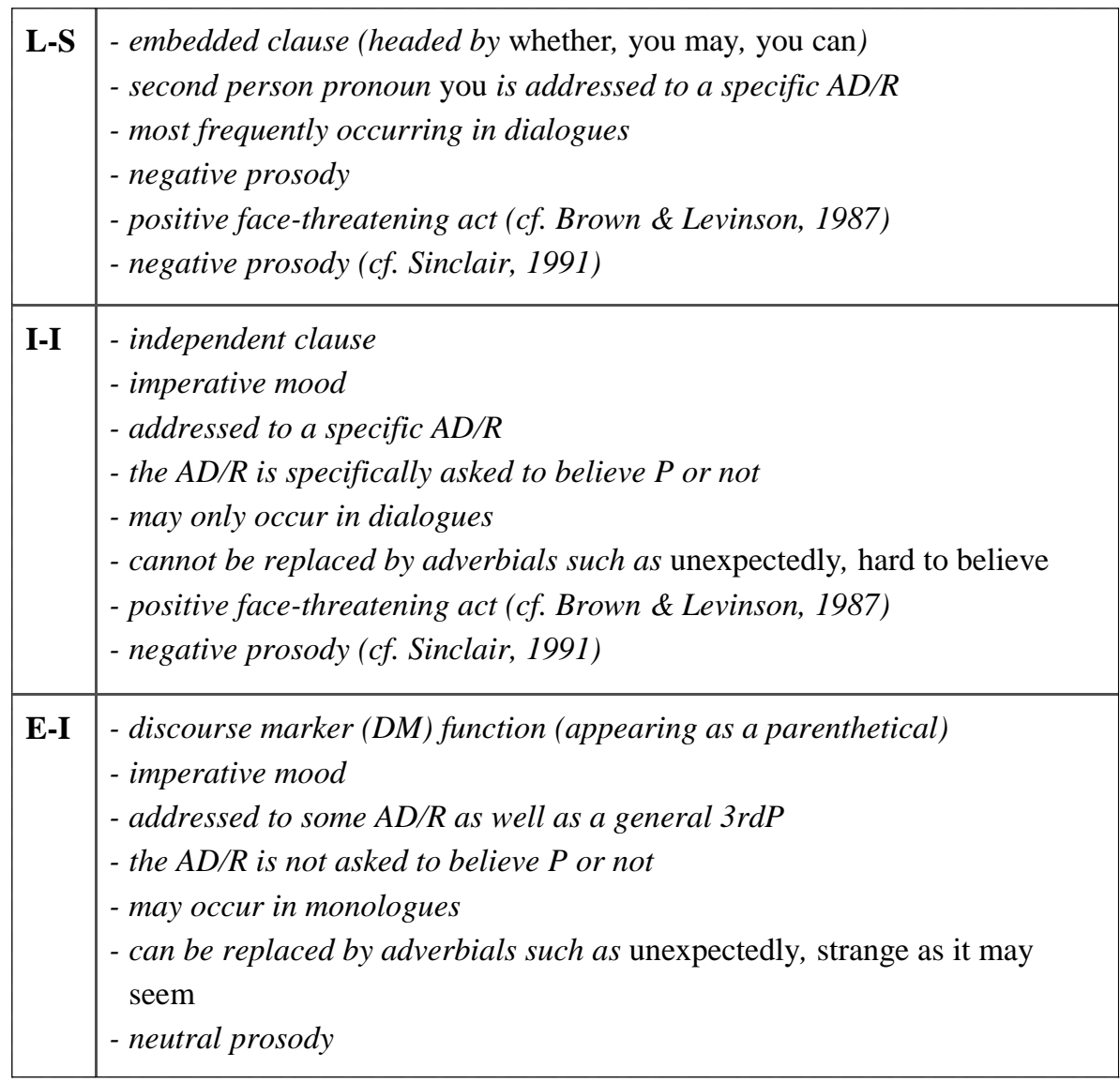

TABLE 3. Criteria adopted for the analysis of the intersubjectification of believe it or not

Based on the criteria given in Table 3, it is possible compare qualitatively L-S with I-I and E-I usages of believe it or not. L-S functions of the construction correspond to instances in which believe it or not is employed literally, without any added meaning which might increase the idiomaticity of the chunk:

$<$ LDIS $>$

[L-S]

(22) Yes, my lady, whether you believe it or not, yourself, you are but little better than a gone $\operatorname{girl}[\ldots]$.

(COHA - Daniel Pierce, The Green Mountain Boys, 1839)

$<\mathrm{X}>$

In (22), believe it or not is embedded in the protasis of a hypothetical construction headed by whether. It is highly compositional and analyzable as it does not show any additional or idiomatic (inter)subjectified meaning other than the literal sum of its parts. 
Consider now the I-I usage of believe it or not given below:

$<$ LDIS $>$

[I-I]

Believe it or not, as you please, I am decided.

(COHA - Daly Augustin, Frou Frou, 1879)

$<\mathrm{X}>$

Cases of I-I as in (23) are characterized by a new employment of the chunk, now occurring as an independent clause in which the awareness of AD/R is conveyed more idiomatically than in (22). This new I-I polysemy is characterized by a less literal meaning, where analyzability and compositionality of the items within the construction are comparatively lower. More specifically, the chunk is now used in the imperative mood, where SP/W gives AD/R two alternatives: believe $P$ and don't believe P. Nonetheless, this I-I form of negative imperative shows low analyzability as it does not occur with the negative auxiliary don't. Similarly, the chunk is not fully compositional, as $\mathrm{SP} / \mathrm{W}$ is not strictly giving an order to $\mathrm{AD} / \mathrm{R}$, but rather intersubjectively considering $\mathrm{AD} / \mathrm{R}$ 's possible epistemic reactions towards what s/he said.

We can now observe an E-I usage of the chunk:

$<$ LDIS $>$

[E-I]

(24) Then I called back Mrs. Frankenthal and, believe it or not, she was free.

(COHA - Edward Streeter, Chairman of the Bored, 1961)

$<\mathrm{X}>$

E-I usages of the chunk such as the one in (24) profile the awareness and potential reactions of a general 3rdP as a possible addressee and show an even lower degree of analyzability and compositionality in comparison with (23). In fact, though formally similar to an I-I construction, believe it or not now occurs as a $\mathrm{DM}$ with a parenthetical function, and $\mathrm{AD} / \mathrm{R}$ is no longer directly asked either to believe $\mathrm{P}$ or not. Rather, SP/W marks his utterance profiling a general 3rdP's potential reaction, as the chunk can now occur in monologues or written registers and can now be replaced with adverbials such as unexpectedly or strange as it may seem:

$<$ LDIS>

[I-I]

(23) (a) *Unexpectedly, as you please, I am decided.

[E-I]

(24) (a) Then I called back Mrs. Frankenthal and, unexpectedly, she was free.

$<\mathrm{X}>$ 
Similar to what we observed for the usages of [you don't want X], even in this case I-I and E-I construals of believe it or not determine the employment of two different speech acts. The former in fact refers to a piece of old information and corresponds to a positive face-threatening act (cf. Brown \& Levinson, 1987) as SP/W expresses the intention of not caring about his/her interactor's feelings or wants. Quite differently, the latter is no longer characterized by a negative prosody ${ }^{25}$ (cf. Sinclair, 1991), as it is used to introduce a piece of new information, the optimal relevance of which is to express the awareness of how anyone would feel while hearing/reading what IS ABOUT TO BE narrated. The neutral prosody of (24) is confirmed by the fact that believe it or not can be felicitously replaced with other parenthetical DMs such as hard to believe or unexpectedly, while this is not possible in (23). In this case, it is also possible to observe a new discourse-oriented function of the E-I construction, now "contributing to the overall coherence of the text or the discourse" (Narrog, 2010, p. 31; 2012, p. 36).

Finally, as we did for the survey about [you don't want X], it is worth considering a couple of bridging examples which can give a diachronic account of the semantic-pragmatic gradience which runs from I-I to E-I usages of believe it or not.

$<$ LDIS $>$

[I-I]

(25) Believe it or not, you poor old back number - retorted Raleigh, hotly. - It alters nothing.

(COHA -John Kendrick Bangs, A House-Boat on the Styx, 1896)

[I-I/E-I]

(26) Believe it or not, it is the truth, and I have the three boys to prove it.

(COHA - Edward Stratemeyer, Dave Porter at Star Ranch, 1910) $<\mathrm{X}>$

To explain, while (25) above can be considered as a prototypical I-I usage of believe it or not, (26) could be analyzed as either a I-I or an E-I construction. That is, while (25) functions unequivocally as an independent clause occurring in the imperative mood and focusing on a specific $\mathrm{AD} / \mathrm{R}$, on the other hand, (26) can either be interpreted as a parenthetical E-I construction functioning as a DM (carrying an impersonal meaning) or also as an I-I chunk addressed to a specific AD/R. In fact, while (25) can only be interpreted as a positive face-threatening act, (26) is ambiguous as it may or may not be characterized by a negative prosody. This is easily demonstrated by the possibility of replacing believe it or not with similar DMs such as unexpectedly or strange as it may seem in (26), while this is clearly more problematic in the case of (25):

\footnotetext{
${ }^{25}$ Negative prosody is here intended from a constructional perspective. That is to say, it takes the whole construction rather than a word - to be perceived with a negative association.
} 
$<$ LDIS $>$

$[\mathrm{I}-\mathrm{I}]$

(25) (a) *Strange as it may seem, you poor old back number - retorted Raleigh, hotly. - It alters nothing.

[I-I/E-I]

(26) (a) Strange as it may seem, it is the truth, and I have the three boys to prove it.

$<\mathrm{X}>$

In Table 4 are summarized all the 217 occurrences of the chunk over the sixteen decades considered:

$<$ Table 4 about here $>$

\begin{tabular}{|c|c|c|c|c|c|c|c|c|c|c|c|c|c|c|c|c|}
\hline & 181 & 182 & 183 & 184 & 185 & 186 & 187 & 188 & 189 & 190 & 191 & 192 & 193 & 194 & 195 & 196 \\
\hline & 0 & 0 & 0 & 0 & 0 & 0 & 0 & 0 & 0 & 0 & 0 & 0 & 0 & 0 & 0 & 0 \\
\hline L-S & 0 & 0 & 2 & 1 & 0 & 4 & 2 & 4 & 4 & 2 & 6 & 6 & 8 & 6 & 3 & 1 \\
\hline I-I & 0 & 0 & 1 & 1 & 1 & 1 & 1 & 1 & 2 & 2 & 3 & 4 & 11 & 8 & 5 & 11 \\
\hline E-I & 0 & 0 & 0 & 3 & 2 & 0 & 0 & 0 & 0 & 1 & 1 & 4 & 18 & 23 & 34 & 30 \\
\hline
\end{tabular}

TABLE 4. The I-I and E-I of believe it or not from the 1810s to the 1960 s

As for the survey in Section 3.2, my first aim was to verify whether the chunk went through an increasing process of intersubjectification throughout the whole period. To achieve this, I first calculated the NF of both I-I and E-I usages of believe it or not per decade, as shown in Figure 7.

Comment [AS30]: Section 3.2:

Please check cross-reference.

>> Change into 5.2 


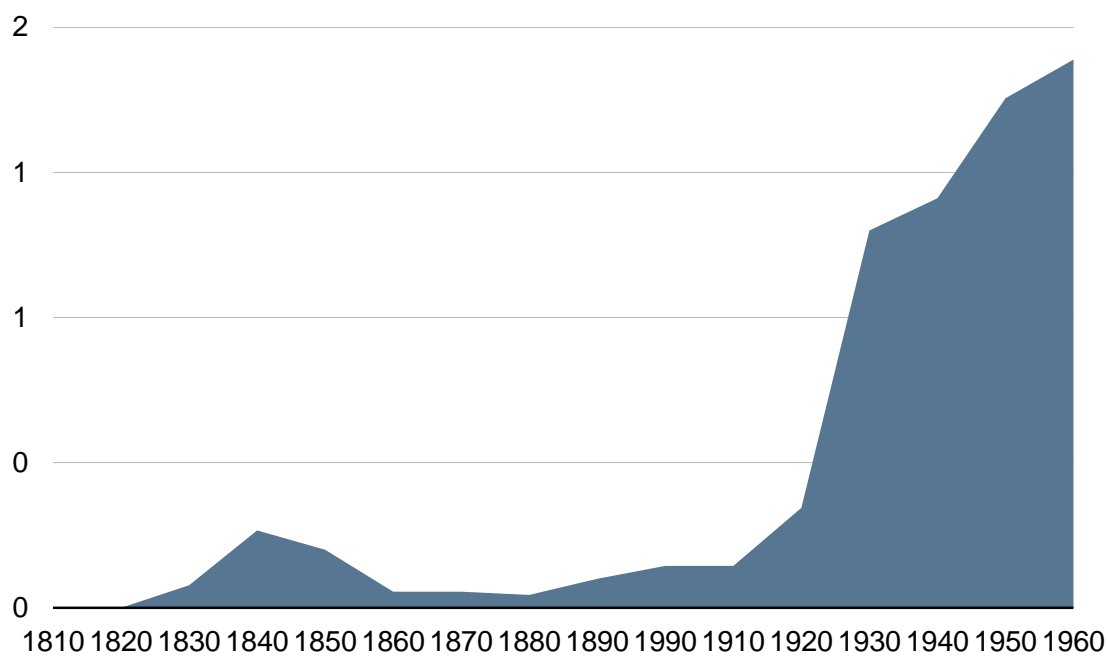

Fig. 7. NF per decade of intersubjectified usages of believe it or not.

As can be observed (the $y$-axis indicates the NF of believe it or not) there is a sharp increase of intersubjectified usages of the construction starting from the beginning of the twentieth century. As could be easily predicted, the intersubjectification occurring from the first eight decades to the second eighty-year time span is statistically significant $(p<.0001)$.

The second hypothesis to be verified was the diachronic continuum from I-I to E-I. Or, in other words, whether I-I usages would constitute a bridging function for the development of further reanalysed E-I ones. A visual account of this phenomenon is provided in Figure 8, where it is possible to observe separately the NF of both I-I and E-I usages of the chunk.

$<$ Figure 8 about here $>$ 


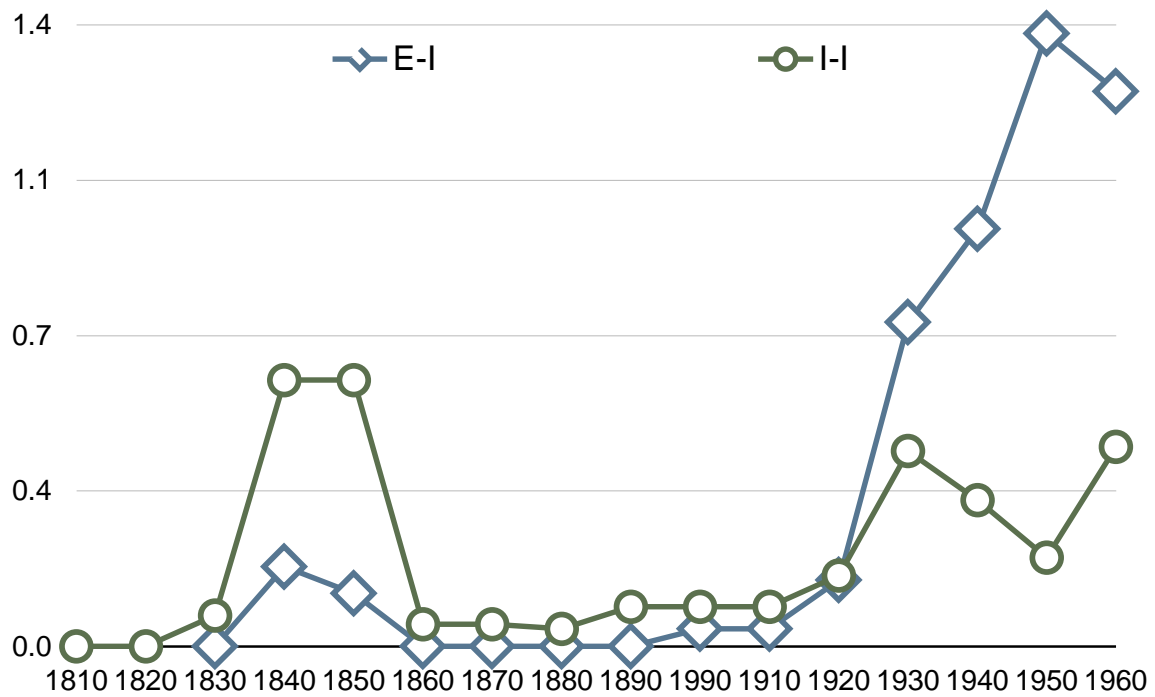

Fig. 8. NF per decade of I-I and E-I usages of believe it or not.

From Figure 8, we can see that from the 1830s up the 1910s, I-I usages of believe it or not are always ahead with respect to E-I ones. Starting from 1920s, despite a sharp increase of the NF of both I-I and E-I functions, the latter abruptly becomes by far the main usage of the chunk. By comparing the two time spans 1810-1880 and 1890-1960, the increased frequency of E-I functions of believe it or not with respect to the overall intersubjectified employment of the chunk is also significant $(p<.0001)$.

To conclude, what these numbers can tell us is that, similar to what we found for [you don't want X], believe it or not also underwent a process of I-I and E-I. Most importantly, E-I occurred as a subsequent stage of reanalysis after an earlier I-I employment of the construction.

\section{Conclusion}

This paper provided a complementing framework to address synchronically and diachronically the hotly debated notion of intersubjectification (Traugott, 1999, 2002, 2003, 2010, 2012; Nuyts, 2001, 2012; Verhagen, 2005; Narrog, 2010, 2012; Dancygier \& Sweetser, 2012). It claims and demonstrates that intersubjectivity can be codified either with respect to an immediate or an extended dimension (cf. Tantucci, 2013, 2014b) the former being bound to the mutual awareness of speaker/writer and addressee/hearer (immediate intersubjectivity), the latter including an assumed third party (specific or generic) who has a social bearing on the utterance (extended

Comment [AS32]: Traugott, ... 2002: Not in Refs.

Change into 'i.e. Traugott \& Dasher 2002; Traugott 2003, 2010, 2012' 
intersubjectivity). It discusses corpus-illustrated and corpus-based data showing that along a unidirectional cline of change (cf. Traugott, 1999, 2002, 2003, 2010, 2012), E-I constitutes a later stage of semantic-pragmatic and/or grammatical reanalysis with respect to its immediate counterpart. I analyzed this phenomenon qualitatively and quantitatively, focusing on specific examples from Mandarin and American English. The diachronic continuum from I-I to E-I presented in this work can constitute an effective theoretical and operational complement to the studies proposed in the literature.

\section{REFERENCES}

Alston, William P. (2000). Illocutionary acts and sentence meaning. Ithaca, NY: Cornell University Press.

Anderson, Lloyd (1986). Evidentials, paths of change, and mental maps: typologically regular asymmetries. In W. Chafe \& J. Nichols (Eds.), Evidentiality: the linguistic coding of epistemology (pp. 273-312). Norwood: Ablex.

Anscombre, Claude J., \& Ducrot, Oswald (1989). Argumentativity and informativity. In M. Meyer (Ed.), From metaphysics to rhetoric (pp. 71-87). Dordrecht: Kluwer.

Baker, Paul, Hardie, Andrew, \& McEnery, Tony (2006). A glossary of corpus linguistics. Edinburgh: Edinburgh University Press.

Benveniste, Emile. 1958. "Subjectivity in language." In Problems in General Linguistics 223-230. Coral Gables: University of Miami Press.

Brinton, Laurel J., \& Traugott, Elizabeth Closs (2005). Lexicalization and language change.

Cambridge: Cambridge University Press.

Brown, Penelope, \& Levinson, Stephen C. (1987). Politeness: some universals in language usage, vol. 4. Cambridge: Cambridge University Press.

Bybee, Joan (2003(.Mechanisms of change in grammaticization: the role of frequency. In B. D. Joseph \& J. Janda (Eds.), The handbook of historical linguistics (pp. 602-623). Oxford: Blackwell.

Bybee, Joan (2010). Language, usage and cognition. Cambridge: Cambridge University Press.

Bybee, Joan, Perkins, Revere, \& Pagliuca, William (1994). The evolution of grammar: tense, aspect, and modality in the languages of the world. Chicago: University of Chicago Press.

Chafe, Wallace (1994). Discourse, consciousness and time: the flow and displacement of conscious experience in speaking and writing. Chicago: University of Chicago Press.

Coates, Jennifer (1983). The semantics of the modal auxiliaries. London: Croom Helm.

Cohen, Jacob, Cohen, Patricia, West, Stephen G., \& Aiken, Leona S. (2013). Applied multiple regression/correlation analysis for the behavioral sciences. New York/London: Routledge.
Comment [AS33]: Traugott, ... 2002: Not in Refs.

Change into 'Traugott \& Dasher 2002; Traugott 2003, 2010, 2012

Comment [AS34]: Alston, William

P. (2000): We can't find a text

reference for this, and so propose to

delete it. Please approve.

>> Approve

Comment [AS35]: Baker, Paul,

Hardie, Andrew, \& McEnery, Tony

(2006): We can’t find a text reference

for this, and so propose to delete it.

Please approve.

$>$ Approve

Comment [AS36]: Chafe, Wallace (1994): We can't find a text reference for this, and so propose to delete it. Please approve.

>> Approve 
Cornillie, Bert (2007). Evidentiality and epistemic modality in Spanish (semi-) auxiliaries: a cognitive-functional approach, vol. 5. Berlin: Walter de Gruyter.

Cornillie, Bert (2009). Evidentiality and epistemic modality: on the close relationship between two different categories. Functions of Language, 16(1), 44-62.

Croft, William (2001). Radical construction grammar: syntactic theory in typological perspective. Oxford: Oxford University Press.

Croft, William (2007). The origins of grammar in the verbalization of experience. Cognitive Linguistics, 18(3), 339-382.

Croft, William (2010). The origins of grammaticalization in the verbalization of experience. Linguistics, 48(1), 1-48.

Croft, William, \& Cruse, D. Alan (2004). Cognitive linguistics. Cambridge: Cambridge University Press.

Dancygier, Barbara, \& Sweetser, Eve (2012). Viewpoint in language: a multimodal perspective. Cambridge: Cambridge University Press.

De Smet, Hendrik, \& Verstraete, Jean-Christophe (2006). Coming to terms with subjectivity. Cognitive Linguistics, 17(3), 365-392.

Fillmore, Charles J, \& Kay, Paul (1999). Grammatical constructions and linguistic generalizations: the What's X doing Y? construction. Language, 75(1), 1-33.

Geeraerts, Dirk. 1997. Diachronic prototype semantics: A contribution to historical lexicology. Oxford: Clarendon.

Goldberg, Adele E. (1995). Constructions: a Construction Grammar approach to argument structure. Chicago: University of Chicago Press.

Goldberg, Adele E. (2006). Constructions at work: the nature of generalization in language. Oxford: Oxford University Press.

Goldman, Alvin I. (2006). Simulating minds: the philosophy, psychology, and neuroscience of mindreading. Oxford: Oxford University Press.

Gregory, Michelle, Raymond, William, Bell, Alan, Fosler-Lussier, Eric, \& Jurafsky, Daniel (1999).

The effects of collocational strength and contextual predictability in lexical production.

Paper presented at the Chicago Linguistic Society, Chicago.

Haiman, John (1994). Ritualization and the development of language. In W. Pagliuca (Ed.), Perspectives on grammaticalization (pp. 3-28). Amsterdam/Philadelphia: John Benjamins.

Haspelmath, Martin (2003). The geometry of grammatical meaning: semantic maps and crosslinguistic comparison. The new psychology of language: cognitive and functional approaches to language structure 2, 211-242.

Heine, Bernd (1992). Grammaticalization chains. Studies in Language, 16(2), 335-368.

Comment [AS40]: Gregory, Michelle, Raymond, William, Bell, Alan, Fosler-Lussier, Eric, \& Jurafsky, Daniel (1999): We can't find a text reference for this, and so propose to delete it. Please approve.

>> Approve

Comment [AS41]: Haspelmath, Martin (2003): Is this entry complete?

>> Delete after the colon ' $:$ cognitive and functional approaches to language structure' 
Hopper, Paul J., \& Traugott, Elizabeth C. (2003). Grammaticalization, 2nd ed.. Cambridge:

Cambridge University Press.

Jary, Mark (2010). Assertion. Palgrave Macmillan.

Jurafsky, Daniel, Bell, Alan, Gregory, Michelle, \& Raymond, William (2001). Probabilistic

relations between words: evidence from reduction in lexical production. In J. Bybee \& P.

Hopper (Eds.), Frequency and the emergence of linguistic structure (pp. 229-254).

Amsterdam/Philadelphia: Benjamins.

Jurafsky, Daniel, Bell, Alan, \& Girand, Cynthia (2002). The role of the lemma in form variation.

Paper presented at Papers in Laboratory Phonology, Berlin/New York.

Kiefer, Ferenc (1984). Focus and modality. Groninger Arbeiten zur Germanistischen Linguistik, 24, 55-81.

Kim, M. S. (2005). Evidentiality in achieving entitlement, objectivity, and detachment in Korean conversation. Discourse Studies, 7(1), 87-108.

Langacker, Ronald W. (1987). Foundations of cognitive grammar: theoretical prerequisites, vol. I.

Stanford, CA: Stanford University Press.

Langacker, Ronald W. (1990). Subjectification. Cognitive Linguistics, 1(1), 5-38.

Langacker, Ronald W. (2002). Concept, image, and symbol. Mouton de Gruyter.

Langacker, Ronald W. (2006). Subjectification, grammaticization, and conceptual archetypes. In C.

Canakis, B. Cornillie, \& A. Athanasiadou (Eds.), Subjectification: various paths to

subjectivity (pp. 17-40). Berlin/New York: Mouton de Gruyter.

Langacker, Ronald W. (2008). Cognitive Grammar: a basic introduction. Oxford: Oxford

University Press.

Lazard, G. (1999). Mirativity, evidentiality, mediativity, or other? Linguistic Typology, 3(1), 91109.

Lazard, G. (2001). On the grammaticalization of evidentiality. Journal of Pragmatics, 33, 359-367.

Leech, Geoffrey N. (1983). Principles of pragmatics. New York: Longman Publishing Group.

Leech, G. N. (1991). The state of the art in corpus linguistics. In K. Aijmer \& B. Altenberg (Eds.),

English corpus linguistics (pp. 8-29). London: Longman.

Levinson, Stephen C. 2000. Presumptive meanings: The theory of generalized conversational implicature. Cambridge, MA: MIT Press.

Locher, Miriam A., \& Graham, Sage L. (2010). Interpersonal pragmatics, vol. 6. Walter de Gruyter.

Lü, Shu Xiang (1999). Xiandai hanyu babai ci [800 words from Modern Mandarin]. Beijing: Commercial Press.

Lyons, John (1982). Deixis and subjectivity: loquor, ergo sum. Speech, place, and action: studies in deixis and related topics (pp. 101-124).
Comment [AS42]: Jary, Mark

(2010): We can't find a text reference for this, and so propose to delete it.

Please approve.

ALSO: If you do keep it, do you have the place of publication?

>> Approve

Comment [AS43]: Jurafsky, Daniel, Bell, Alan, Gregory, Michelle, \& Raymond, William (2001): We can't find a text reference for this, and so propose to delete it. Please approve.

\section{>> Approve}

Comment [AS44]: Jurafsky, Daniel, Bell, Alan, \& Girand, Cynthia (2002): We can't find a text reference for this, and so propose to delete it. Please approve.

ALSO: If you do keep it, can you please confirm the two locations?

\section{$>$ Approve}

Comment [AS45]: Kiefer, Ferenc (1984): We can't find a text reference for this, and so propose to delete it.

Please approve.

$>$ Approve

Comment [AS46]: Kim, M. S. (2005): We can't find a text reference for this, and so propose to delete it. Please approve.

$>$ Approve

Comment [AS47]: Langacker, Ronald W. (2002): Do you have the place of publication?

$>>$ Berlin

Comment [AS48]: Lazard, G. (1999): We can't find a text reference for this, and so propose to delete it. Please approve.

>> Approve

Comment [AS49]: Lazard, G. (2001): We can't find a text reference for this, and so propose to delete it. Please approve.

>> Approve

Comment [AS50]: Locher, Miriam A., \& Graham, Sage L. (2010): Place of publication?

>> Berlin

Comment [AS51]: Lyons, John (1982): Is this entry complete?

Lyons, John (1982)

Deixis and subjectivity: loquor, ergo sum 
Martin, James R., \& White, Peter R. R. (2005). The language of evaluation. Basingstoke/New

York: Palgrave Macmillan.

Mushin, Ilana (2001). Evidentiality and epistemological stance. Amsterdam: Benjamins.

Narrog, Heiko (2010). Modality and speech-act orientation. Paper presented at Grammaticalization and (Inter-)Subjectification, Brussels.

Narrog, Heiko (2012). Beyond intersubjectification: textual usages of modality and mood in subordinate clauses as part of speech orientation. English Text Construction, 5(1), 29-52.

Newell, Allen (1990). Unified theories of cognition. Cambridge, MA: MIT Press.

Nuyts, Jan (2001). Subjectivity as an evidential dimension in epistemic modal expressions. Journal of Pragmatics, 33, 383-400.

Nuyts, Jan (2012). Notions of (inter) subjectivity. English Text Construction, 5(1), 53-76.

Premack, David, \& Woodruff, Guy (1978). Does the chimpanzee have a theory of mind? Behavioral and Brain Sciences, 1(4), 515-526.

Qiang, Xing Na (2007). Tawen yu ziwen - cong putonghua 'ma' he 'ne’ shuoqi [Third-person and reflexive questions. A discussion on Mandarin 'ma' and 'ne']. Yuyan Kexue, 5.

Qiang, Xing Na (2008). Zhiqing zhuangtai yu zhichen yuqici 'ma' [Factual modality and the indicative mood particle 'ma']. Shijie Hanyu Jiaoxue, 2.

Rayson, Paul, \& Garside, Roger (2000). Comparing corpora using frequency profiling. Paper presented at Proceedings of the Workshop on Comparing Corpora.

Rayson, Paul, Berridge, Damon, \& Francis, Brian (2004). Extending the Cochran rule for the comparison of word frequencies between corpora. Paper presented at the 7th International Conference on Statistical Analysis of Textual Data (JADT 2004).

Schriffin, Deborah (1990). The principle of intersubjectivity in communication and conversation. Semiotica, 80, 121-151.

Schwenter, Sott A., \& Waltereit, Richard (2010). Presupposition accommodation and language change. In K. Davidse \& L. Vandelanotte (Eds.), Subjectification, intersubjectification and grammaticalization (pp. 75-102). Berlin: De Gruyter Mouton.

Shen, Li (2003). Hanyu de zhichen yutai fanchou, jian zhongguo yuwen zazhi shebian 'yufa yanjiu he tansuo' (12) [The indicative mood of Mandarin: a look at the linguistic journal research and explorations in grammar (12)]. Beijing: Commercial Press.

Sinclair, J. M. (1991). Corpus, concordance, collocation. Oxford: Oxford University Press.

Slobin, D., \& Aksu, K. A. (1982). Tense, aspect, and modality in the use of the Turkish evidential. In P. Hopper (Ed.), Tense-aspect: between semantics and pragmatics (pp. 185-200). Amsterdam: Benjamins. 
Slobin, D., \& Aksu, K. A. (1986). A psychological account of the development and use of evidentials in Turkish. In W. Chafe \& J. Nichols (Eds.), Evidentiality: the linguistic coding of epistemology (pp. 159-167). Norwood: Ablex.

Smith, Carlota S. (2003). Modes of discourse: the local structure of texts, vol. 103. Cambridge: Cambridge University Press.

Sperber, D., \& Wilson, D. (1995). Relevance: communication and cognition. Oxford: Blackwell.

Sweetser, Eve E. 1990. From etymology to pragmatics: Metaphorical and cultural aspects of semantic structure. Cambridge: Cambridge University Press.

Talmy, Leonard (2000). Toward a cognitive semantics, vol. 1. Cambridge, MA: MIT Press.

Tantucci, Vittorio (2013). Interpersonal evidentiality: the Mandarin V-过 guo construction and other evidential systems beyond the 'source of information'. Journal of Pragmatics, 57, 210-230.

Tantucci, Vittorio (2014a). Epistemic inclination and factualization: a synchronic and diachronic study on the semantic gradience of factuality. Language and Cognition. doi: 10.1017/langcog.2014.34.

Tantucci, Vittorio (2014b). Immediate and extended intersubjectivity: synchronic and diachronic interplay among evidentiality, factuality and other domains. Unpublished $\mathrm{PhD}$ dissertation, Lancaster University.

Tantucci, Vittorio (2015 in press). Traversativity and grammaticalization: the aktionsart of 过 guo as a lexical source of evidentiality Chinese Language and Discourse.

Traugott, Elizabeth Closs (1989). On the rise of epistemic meanings in English: an example of subjectification in semantic change. Language, 31-55.

Traugott, Elizabeth Closs (1999). From subjectification to intersubjectification. Paper presented at Fourteenth International Conference on Historical Linguistics, Vancouver, Canada.

Traugott, Elizabeth Closs (2003). From subjectification to intersubjectification. In R. Hickey (Ed.), Motives for language change (pp. 124-139). Cambridge: Cambridge University Press.

Traugott, Elizabeth Closs (2010). Revisiting subjectification and intersubjectification. In K. Davidse \& L. Vandelanotte (Eds.), Subjectification, intersubjectification and grammaticalization (pp. 29-70). Berlin: De Gruyter Mouton.

Traugott, Elizabeth Closs (2012). Intersubjectification and clause periphery. English Text Construction, 5(1), 7-28.

Traugott, Elizabeth Closs, \& Dasher, Richard B. (2002). Regularity in semantic change. Cambridge: Cambridge University Press.

Traugott, Elizabeth Closs, \& Trousdale, Graeme (2013). Constructionalization and constructional changes. Oxford: Oxford University Press.
Comment [AS58]: Slobin, D., \& Aksu, K. A. (1986): We can’t find a text reference for this, and so propose to delete it. Please approve.

>> Approve.

Comment [AS59]: Talmy, Leonard (2000): We can't find a text reference for this, and so propose to delete it. Please approve.

$>$ Approve

Comment [AS60]: Tantucci, Vittorio (2014a): Is this now published?

>> It is now published.

Tantucci, Vittorio. 2015. "Epistemic inclination and factualization: a synchronic and diachronic study on the semantic gradience of factuality." Language and Cognition 7 (3):371-414

Comment [AS61]: Tantucci, Vittorio (2015 in press): Is this now published?

>> It is now published.

Tantucci, Vittorio. 2015 "Traversativity and grammaticalization: The aktionsart of 过 guo as a lexical source of evidentiality." Chinese Language and Discourse 6 (1):57-100.

Comment [AS62]: Traugott,

Elizabeth Closs (1989): Do you have the volume number?

$>>65$ 
Trousdale, Graeme (2012). Grammaticalization, constructions and the grammaticalization of constructions. In K. Davidse, T. Breban, L. Brems, \& T. Mortelmans (Eds.),

Grammaticalization and language change (pp. 167-198). Amsterdam: Benjamins.

Tummers, José, Heylen, Kris, \& Geeraerts, Dirk (2005). Usage-based approaches in cognitive linguistics: a technical state of the art. Corpus Linguistics and Linguistic Theory, 1(2), 225261.

Van der Auwera, Johan, \& Plungian, Vladimir A. (1998). Modality’s semantic map. Linguistic Typology, 2(1), 79-124.

Verhagen, Arie (2005). Constructions of intersubjectivity: discourse, syntax and cognition. Oxford: Oxford University Press.

Watts, Richard (1984). An analysis of epistemic possibility and probability. English Studies, 65, 129-140.

White, Peter R. R. (2003). Beyond modality and hedging: a dialogic view of the language of intersubjective stance. Text-the hague then Amsterdam then Berlin- 23(2), 259-284. 